\title{
əImpact of Multidecadal Variability in Atlantic SST on Winter Atmospheric Blocking
}

\author{
Young-Oh Kwon, Hyodae Seo, Caroline C. Ummenhofer, And Terrence M. Joyce \\ Woods Hole Oceanographic Institution, Woods Hole, Massachusetts
}

(Manuscript received 3 May 2019, in final form 10 October 2019)

\begin{abstract}
Recent studies have suggested that coherent multidecadal variability exists between North Atlantic atmospheric blocking frequency and the Atlantic multidecadal variability (AMV). However, the role of AMV in modulating blocking variability on multidecadal times scales is not fully understood. This study examines this issue primarily using the NOAA Twentieth Century Reanalysis for 1901-2010. The second mode of the empirical orthogonal function for winter (December-March) atmospheric blocking variability in the North Atlantic exhibits oppositely signed anomalies of blocking frequency over Greenland and the Azores. Furthermore, its principal component time series shows a dominant multidecadal variability lagging AMV by several years. Composite analyses show that this lag is due to the slow evolution of the AMV sea surface temperature (SST) anomalies, which is likely driven by the ocean circulation. Following the warm phase of AMV, the warm SST anomalies emerge in the western subpolar gyre over 3-7 years. The ocean-atmosphere interaction over these 3-7-yr periods is characterized by the damping of the warm SST anomalies by the surface heat flux anomalies, which in turn reduce the overall meridional gradient of the air temperature and thus weaken the meridional transient eddy heat flux in the lower troposphere. The anomalous transient eddy forcing then shifts the eddy-driven jet equatorward, resulting in enhanced Rossby wave breaking and blocking on the northern flank of the jet over Greenland. The opposite is true with the AMV cold phases but with much shorter lags, as the evolution of SST anomalies differs in the warm and cold phases.
\end{abstract}

\section{Introduction}

Atmospheric blocking is a weather phenomenon characterized most often by an anomalous anticyclone on weekly time scales, which blocks or diverts the jet stream (Rex 1950a,b). Blocking often accompanies extreme weather events, such as droughts, heat waves, and high winds (e.g., Sillmann and Croci-Maspoli 2009; Coumou and Rahmstorf 2012). As blocks can occur over a significant portion of a season, blocking occurrence substantially impacts the seasonal mean circulation variability. For example, winter blocking frequency in the North Atlantic region is shown to be highly correlated with the North Atlantic Oscillation (NAO), the region's leading mode of atmospheric circulation variability (Scherrer et al. 2006; Woollings et al. 2008; Davini et al. 2012). In particular, winters with more blocking days over Greenland and Scandinavia are likely to occur during the negative NAO

๑ Denotes content that is immediately available upon publication as open access.

Corresponding author: Young-Oh Kwon, yokwon@whoi.edu phase. On the other hand, increased incidence of blocking days over western Europe and the subtropical North Atlantic is associated with the positive phase of NAO.

Blocking often results from Rossby wave breaking on the flank of the eddy-driven jet (Pelly and Hoskins 2003; Woollings et al. 2008). Wave breaking occurs when the amplitude of the meandering jet associated with the Rossby wave becomes sufficiently large and nonlinear (McIntyre and Palmer 1983). Depending on the latitude of the jet, the preferred location of the wave breaking changes. When the jet moves equatorward (poleward), the cyclonic Rossby wave breaking increases (decreases) on the northern flank of the jet over Greenland (Barnes and Hartmann 2010; Michel and Rivière 2011). Rossby wave breaking and jet variability are intrinsically associated with the leading modes of variability for the mean circulation pattern, including the NAO (Benedict et al. 2004; Strong and Magnusdottir 2008; Woollings et al. 2008, 2010; Davini and Cagnazzo 2014).

Recent studies suggested that the variability in the jet latitude and Rossby wave breaking are driven by the transient eddy forcing (Woollings et al. 2011; Novak et al. 2015; O'Reilly et al. 2016b, 2017a). Novak et al. (2015) 
showed that the changes in the low-level transient eddy heat flux are associated not only with changes of the baroclinicity in the upstream western North Atlantic, but also with a shift in the jet latitude downstream in the eastern North Atlantic. The upstream eddy heat flux induces changes in eddy anisotropy, which affects the dominant type of wave breaking and the latitude of the jet downstream. For example, enhanced upstream eddy heat flux is conducive to anticyclonic wave breaking and a northward shift of the jet. O'Reilly et al. (2017a) also found a similar relationship between the upstream eddy heat flux and the downstream jet latitude in a reanalysis as well as an AGCM simulation. Furthermore, O'Reilly et al. (2017a) showed that the large SST gradient along the Gulf Stream is important for inducing the high eddy heat flux in the Gulf Stream region.

In addition to the intraseasonal to interannual variability, the North Atlantic climate exhibits multidecadal variability, namely the Atlantic multidecadal variability (AMV) or also called Atlantic multidecadal oscillation (AMO; Kerr 2000). The AMV is defined as the SST anomaly averaged over the entire North Atlantic (Enfield et al. 2001) and has been shown to impact weather and climate around the North Atlantic, such as hurricane activity (Goldenberg et al. 2001; Smith et al. 2010) and precipitation in North America, Europe, and northern Africa (Folland et al. 1986; Sutton and Hodson 2005; Zhang and Delworth 2006; Sutton and Dong 2012; Kushnir et al. 2010; Ting et al. 2011; García-García and Ummenhofer 2015; Ruprich-Robert et al. 2017). The impact of AMV is seasonally dependent. For example, O'Reilly et al. (2017b) found that in summer, warmer surface air temperature anomalies over western Europe during the warm AMV phase are mainly due to the thermodynamic influence of warmer North Atlantic Ocean. On the other hand in winter, they found colder surface air temperature over parts of western Europe is due to the atmospheric circulation response to the warm AMV (O'Reilly et al. 2017b).

Recent studies suggest that the AMV also influences the NAO in wintertime (Peings and Magnusdottir 2014, 2016; Omrani et al. 2014; Gastineau and Frankignoul 2015). These studies show that the warm phase of AMV is followed by negative NAO after approximately 3 years. Considering the close relationship among blocking, Rossby wave breaking, and the NAO, it is possible that AMV could also influence the statistics of atmospheric blocking. However, involved mechanisms tend to differ among the modeling studies. For example, Omrani et al. $(2014,2016)$ found that the stratosphere plays a crucial role in the NAO response to AMV. On the other hand, Peings and Magnusdottir (2016) did not find any sensitivity of the NAO response to AMV to the representation of the stratosphere in the atmospheric general circulation models (AGCMs).

Häkkinen et al. (2011a) reported a multidecadal modulation in the wintertime blocking frequency over the subpolar North Atlantic coherently varying with the AMV. They suggested that the wind stress curl variability over the North Atlantic associated with its second empirical orthogonal function (EOF) mode drives the AMV (also Häkkinen et al. 2011b). The second EOF mode of the wind stress curl is linked to the eastern Atlantic teleconnection pattern (Barnston and Livezey 1987) and also blocking variability over the subpolar North Atlantic. However, a question is left unanswered: why atmospheric blocking variability exhibits such a noticeable multidecadal component and whether it reflects any influence from the AMV and/or the two-way coupled mode of variability between the atmospheric blocking and AMV (cf. Woollings 2011).

Davini et al. (2015) performed AGCM experiments forced with AMV SST anomalies added to the climatological mean SST. They found the blocking frequency to be increased over Greenland and reduced over the subtropical North Atlantic in response to the warm AMV phase. Based on additional sensitivity experiments, they further demonstrated that the North Atlantic blocking response is mostly due to the tropical part $\left(0^{\circ}-30^{\circ} \mathrm{N}\right)$ of the AMV SST anomalies, while the extratropical $\left(30^{\circ}-70^{\circ} \mathrm{N}\right)$ AMV anomalies exert a negligible impact. In contrast, using different models and slightly different SST anomalies, Peings and Magnusdottir $(2014,2016)$ and Gastineau et al. (2016) suggested, based on their AGCM experiments, that the extratropical part of the AMV SST anomalies is the dominant driver of the atmospheric circulation responses. This result is consistent with Gastineau and Frankignoul's (2015) study based on statistical analyses of a reanalysis dataset, which also demonstrated a critical role of the extratropical part of the AMV SST anomalies in driving the atmospheric circulation responses by perturbing the storm track.

In this study, we examine the impact of AMV SST anomalies on the multidecadal wintertime blocking variability for 1901-2010 based on multiple observational and reanalysis datasets. The datasets and the analysis methods are briefly described in section 2 . The main results are presented in section 3, which is followed by the summary and discussion in section 4 .

\section{Data and methods}

\section{a. Atmospheric reanalysis and SST datasets}

For the SST, the monthly data from the Hadley Center Sea Ice and Sea Surface Temperature (HadISST) version 
1.1 at $1^{\circ}$ resolution (Rayner et al. 2003) for 1901-2010 are used. HadISST provides monthly mean gridded global SST and sea ice fields from 1871 to present. It uses reduced space optimal interpolation applied to SSTs from the Met Office Marine Data Bank (Parker et al. 1995) and the International Comprehensive Ocean-Atmosphere Dataset (ICOADS; Woodruff et al. 2011) through 1981 and a blend of in situ and adjusted satellite-derived SSTs for 1982 onward. The NOAA Extended Reconstructed Sea Surface Temperature (ERSST) version 5 for 19012010 at $2^{\circ}$ resolution (Huang et al. 2017) is also used to assess the robustness of our results based on the HadISST. A comparison between the two datasets is presented in appendix $\mathrm{C}$.

For the atmospheric variables and surface heat fluxes, the daily and monthly mean variables at $2^{\circ}$ horizontal resolution from the NOAA Twentieth Century Reanalysis version 2 (hereafter simply 20CR; Compo et al. 2006, 2011) are used for 1901-2010. The 20CR provides a 56-member ensemble as well as the ensemble mean fields since 1850 by assimilating only the surface pressure and using HadISST1.1 SST and sea ice concentration as boundary conditions. We have analyzed all 56 members for the blocking statistics (appendix A). The North Atlantic blocking statistics in 20CR exhibit a very small ensemble spread for the study period (see Fig. A1 in appendix A), which suggests that the assimilated surface pressure data and the prescribed SST and sea ice concentration boundary conditions predominantly constrain the reanalysis fields at least for the variables of interest here. Therefore, we use the ensemble mean fields for the rest of the paper.

We also use the ECMWF atmospheric reanalysis of the twentieth century (ERA-20C; Poli et al. 2015) to further assess the robustness of the findings based on 20CR. The ERA-20C for 1901-2010 is downloaded at $2^{\circ}$ horizontal resolution. A comparison with 20CR for the key results is presented in appendix B. Overall, the two independent century-long reanalyses provide very consistent results in the blocking statistics as well as their relationship with the AMV.

The multidecadal nature of AMV requires an analysis period of a century or longer. While some of the above SST and atmospheric datasets provide data prior to 1900 , we use 1901-2010 as our analysis period, the common period for all four datasets. This analysis period allows direct comparison with the previous studies on the AMV and its relationship to the atmospheric circulation using similar periods (e.g., Häkkinen et al. 2011a; O'Reilly et al. 2017b).

\section{b. Definitions for the AMV, blocking, storm track, jet} latitude, and $N A O$

The AMV index is defined as the annual mean SST anomalies averaged over the North Atlantic $\left(0^{\circ}-60^{\circ} \mathrm{N}\right.$,
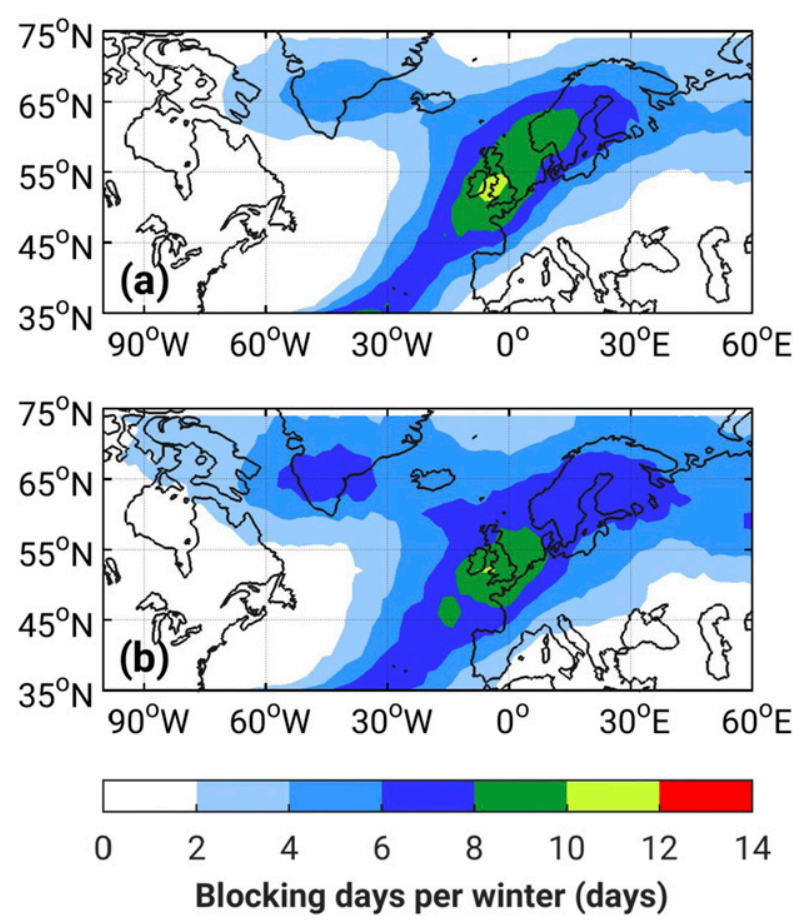

FIG. 1. (a) Climatological mean and (b) interannual standard deviation of the winter (December-March) number of blocking days for 1901-2010 based on the ensemble mean daily Z500 of the NOAA Twentieth Century Reanalysis (20CR).

$80^{\circ} \mathrm{W}-10^{\circ} \mathrm{E}$ ) after removing the externally forced component at each grid point. Following Ting et al. (2009), the externally forced component is calculated by regressing the SST anomalies at each grid point on the global $\left(60^{\circ} \mathrm{S}-60^{\circ} \mathrm{N}\right)$ mean surface temperature from HadCRUT3 (Jones et al. 1999). Note that this AMV definition is also used by Häkkinen et al. (2011a). We use the AMV index both before and after applying a 10 -yr low-pass filter as noted below.

Blocking days are defined using the meridional gradient of the daily 500-hPa geopotential height (Z500) (Scherrer et al. 2006), which is a two-dimensional version of the commonly used one-dimensional definition by Tibaldi and Molteni (1990). Note that this is the same blocking day definition used by Häkkinen et al. (2011a). On each day, at a given location, the Z500 meridional gradients are calculated against the locations $16^{\circ}$ to the north and south, respectively:

$$
\begin{aligned}
\Delta \mathrm{Z500}_{S} & =\frac{\mathrm{Z} 500\left(x_{0}, y_{0}\right)-\mathrm{Z} 500\left(x_{0}, y_{S}\right)}{y_{0}-y_{S}}, \\
\Delta \mathrm{Z} 500_{N} & =\frac{\mathrm{Z} 500\left(x_{0}, y_{N}\right)-\mathrm{Z} 500\left(x_{0}, y_{0}\right)}{y_{N}-y_{0}},
\end{aligned}
$$

where $x_{0}$ and $y_{0}$ are the target longitude and latitude, respectively, while $y_{S}=y_{0}-16$ and $y_{N}=y_{0}+16$. 

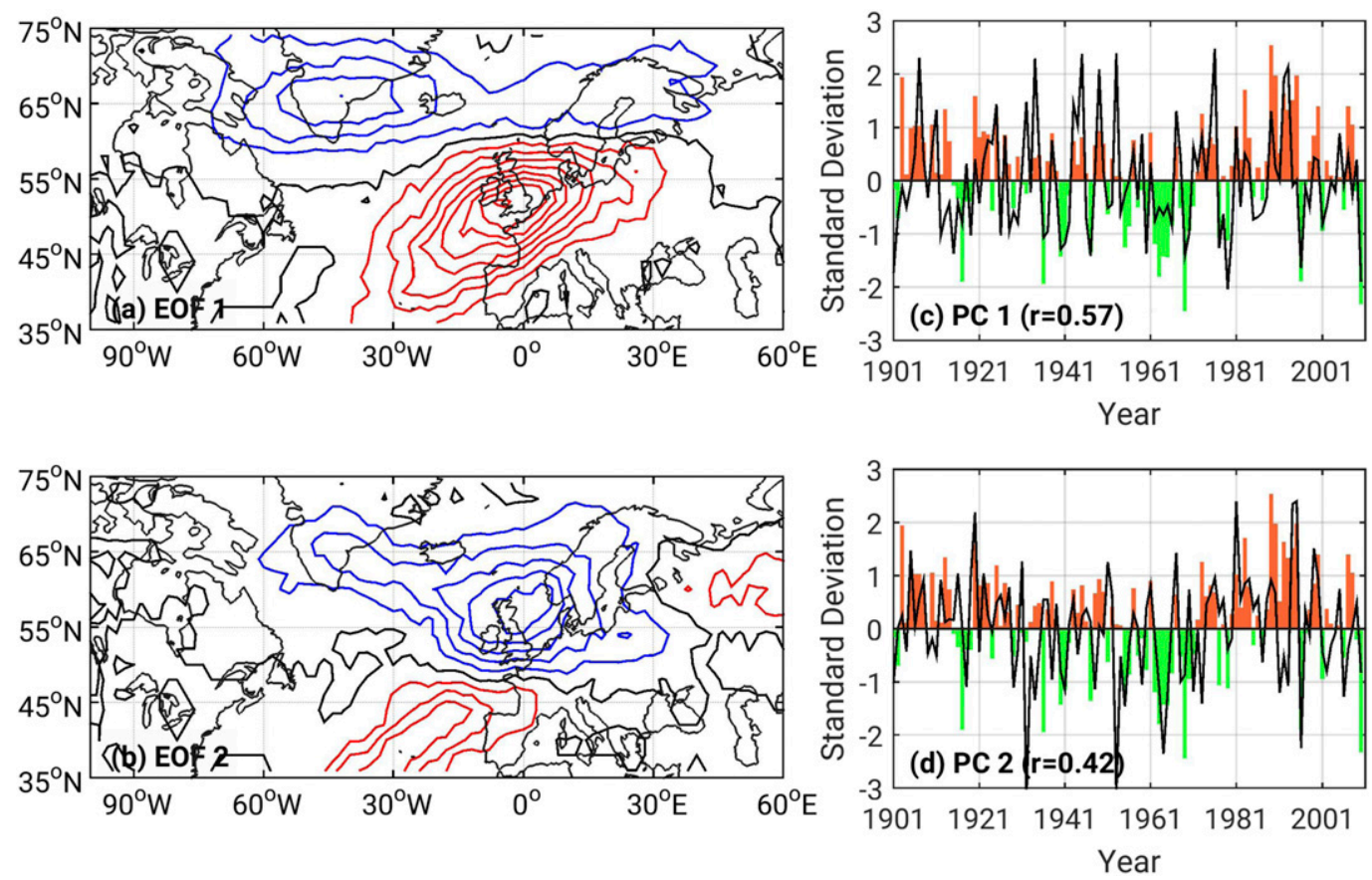

FIG. 2. (a),(b) Leading EOF patterns of the winter (December-March) number of blocking days for 1901-2010 based on the ensemble mean field of 20CR. These two EOFs explain $19.1 \%$ and $10.7 \%$ of the total variance, respectively. Note that the amplitudes of the patterns correspond to one standard deviation of the corresponding PC time series. Red (blue) contours indicate positive (negative) anomalies. Contour intervals are 1 day. (c), (d) The corresponding PC time series (black curves) and the NAO index time series (orange and green bars). The correlation between each PC time series and NAO index is shown in parentheses.

When a block is present, the gradient to the south is expected to be reversed $\left(\Delta \mathrm{Z} 500_{S}>0\right)$ (Lejanäs and $\varnothing$ kland 1983). An additional criterion for the gradient to the north $\left(\Delta \mathrm{Z} 500_{N}<-10 \mathrm{~m}\right.$ per degree of latitude $)$ is imposed to ensure a westerly wind to the north of the block as the jet is being split around the blocking (Tibaldi and Molteni 1990; Barnes et al. 2012). When these two criteria are satisfied at any given point in space and time, an instantaneous block is identified. If instantaneous blocks are found for five consecutive days or longer at a location, those days are identified as the blocking days. We have not considered any additional criterion to further account for spatial and temporal coherences (e.g., Barnes et al. 2012).

The storm track is defined as the atmospheric transient eddy heat flux $\overline{v^{\prime} T^{\prime}}$ on the synoptic time scale (2-8 days) at $850 \mathrm{hPa}$. The daily meridional wind $v$ and air temperature $T$ at $850 \mathrm{hPa}$ are high-pass filtered at 8 days using the Lanczos filter with 15 weights (Duchon 1979), and their covariance is calculated for each winter, December-March (Kwon and Joyce 2013). In addition to the winter mean covariance, the daily low-frequency transient eddy heat flux is calculated based on the 9-day moving average of daily $v^{\prime} T^{\prime}$, similar to Novak et al. (2015) and O'Reilly et al. (2017a).
The daily jet latitude is defined using the daily $850-\mathrm{hPa}$ zonal wind (Woollings et al. 2010; Davini and Cagnazzo 2014; Kwon et al. 2018). The daily 850-hPa zonal wind is first zonally averaged from $75^{\circ} \mathrm{W}$ to $15^{\circ} \mathrm{E}$ and temporally smoothed using a 5-day running mean (Davini and Cagnazzo 2014). Subsequently, the latitude with the maximum wind speed is identified as the jet latitude for each day. Note that we also used a different zonal average (e.g., from $60^{\circ} \mathrm{W}$ to $0^{\circ} \mathrm{E}$ ) and found that the result is not sensitive to this choice.

The NAO index is defined based on the difference between the normalized sea level pressure at Lisbon, Portugal, and Stykkisholmur/Reykjavik, Iceland (Hurrell 1995). The station-based index is downloaded from the Climate Data Guide (https://climatedataguide.ucar.edu/).

\section{c. Statistical analyses}

The winter (December-March) mean is used for all the variables except for the AMV index, which uses the annual mean. The winter means are assigned to the years of January; for example, the average from December 1990 to March 1991 is assigned to the 1991 winter mean. So, there is an implied lag of a few months when a winter variable and the annual AMV in the same year are compared. All the analyses are for 1901-2010, 

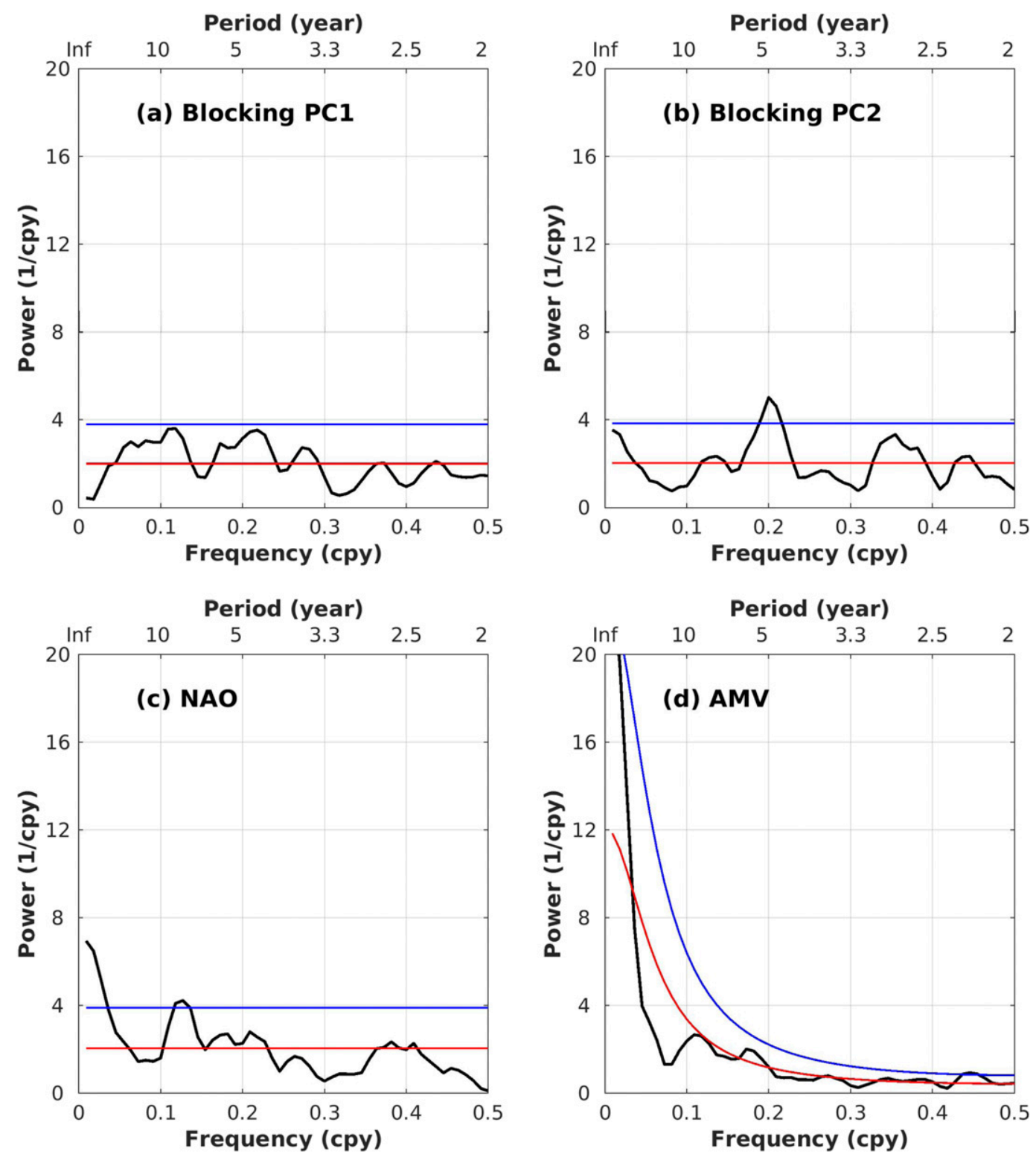

FIG. 3. Power spectra of the normalized (a) blocking days PC1, (b) blocking days PC2, (c) NAO index, and (d) AMV index, showing in (a)-(c) the white noise spectra as the null hypothesis (red lines) and associated 5\% significance levels (blue lines) and in (d) the best-fit first-order autoregressive model spectra and associated 5\% significance levels are plotted with red and blue lines, respectively, based on the 1-yr lag autocorrelation of the respective time series.

as already stated. The climatological mean and linear trend are removed from all the variables before any statistical analysis. We simply remove the linear trend instead of externally forced component as for the AMV index, because the externally forced component in the atmospheric circulation is hardly detectable (e.g., Deser et al. 2012), and there is no generally accepted method for atmospheric circulation variables. Also the linear trend is very small in the atmospheric circulation.
The EOFs are calculated based on the covariance matrix after the weights proportional to the square root of the area are applied. The principal component (PC) time series are normalized, and the EOF spatial patterns are calculated as a regression on the corresponding PC time series. Hence the EOF spatial patterns show the typical amplitude corresponding to the one standard deviation fluctuation of the PC time series. 

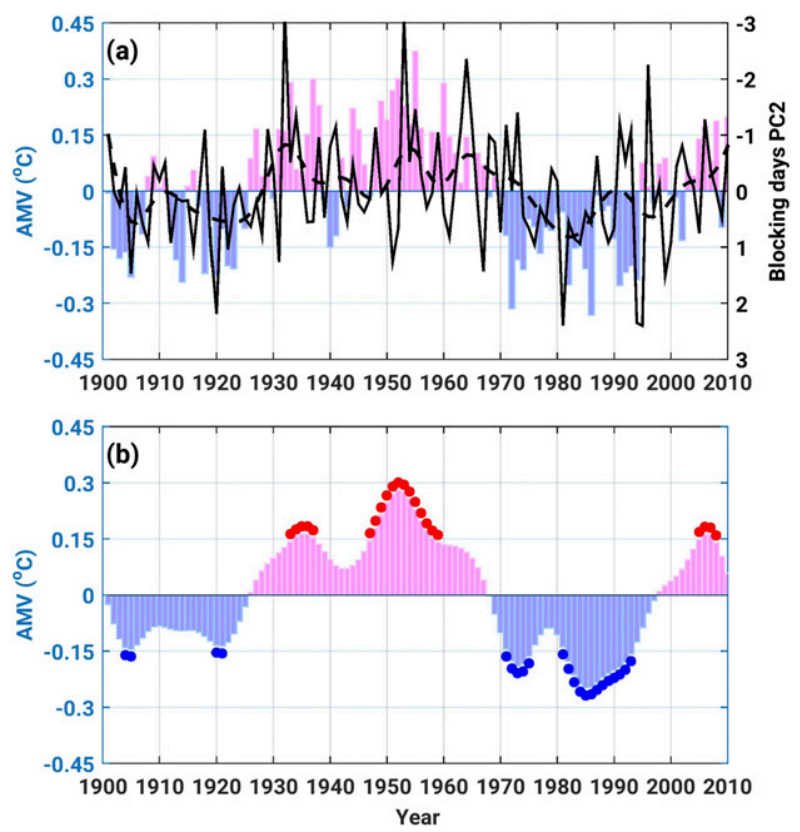

FIG. 4. (a) The second PC time series of the winter number of blocking days (black solid curve). The 10-yr low-pass filtered PC time series is also plotted as the black dashed curve. The annual mean AMV index is shown as the pink and purple bars. (b) The 10-yr low-pass filtered AMV index. The red and blue dots indicate the top and bottom 20th percentile years, respectively, which are used for the composite analyses.

For the composite analysis based on the top and bottom 20 percentile years, respectively, of the $10-\mathrm{yr}$ low-pass filtered AMV time series, a binomial smoothing $(1 / 4-1 / 2-1 / 4)$ is applied to the composited variables before compositing to slightly boost the signal-to-noise ratio (Taguchi et al. 2012; Gastineau and Frankignoul 2015), but no further low-pass filtering is applied to the composited variables. (Note that the binomial smoothing is only used for the composite analysis.) The results are not sensitive to the exact choice of the percentile threshold. To avoid misinterpreting a teleconnection from the tropical Indo-Pacific affecting both the AMV index and composited variables as a local interaction between AMV and composited variables, we minimize the remote tropical Indo-Pacific influence from the AMV index and all the composited variables prior to the composite analysis (Frankignoul and Kestenare 2002; Frankignoul et al. 2011). To this end, the linear regression of AMV and composited variables on the three leading PCs of the tropical Indo-Pacific $\left(15^{\circ} \mathrm{S}-15^{\circ} \mathrm{N}\right.$, $30^{\circ} \mathrm{E}-70^{\circ} \mathrm{W}$ ) SST are calculated from monthly data and subtracted from the full AMV index and composited variables. The regressions are calculated with a lag of one month for the tropical Indo-Pacific PCs leading the Atlantic variables. However, when the atmospheric
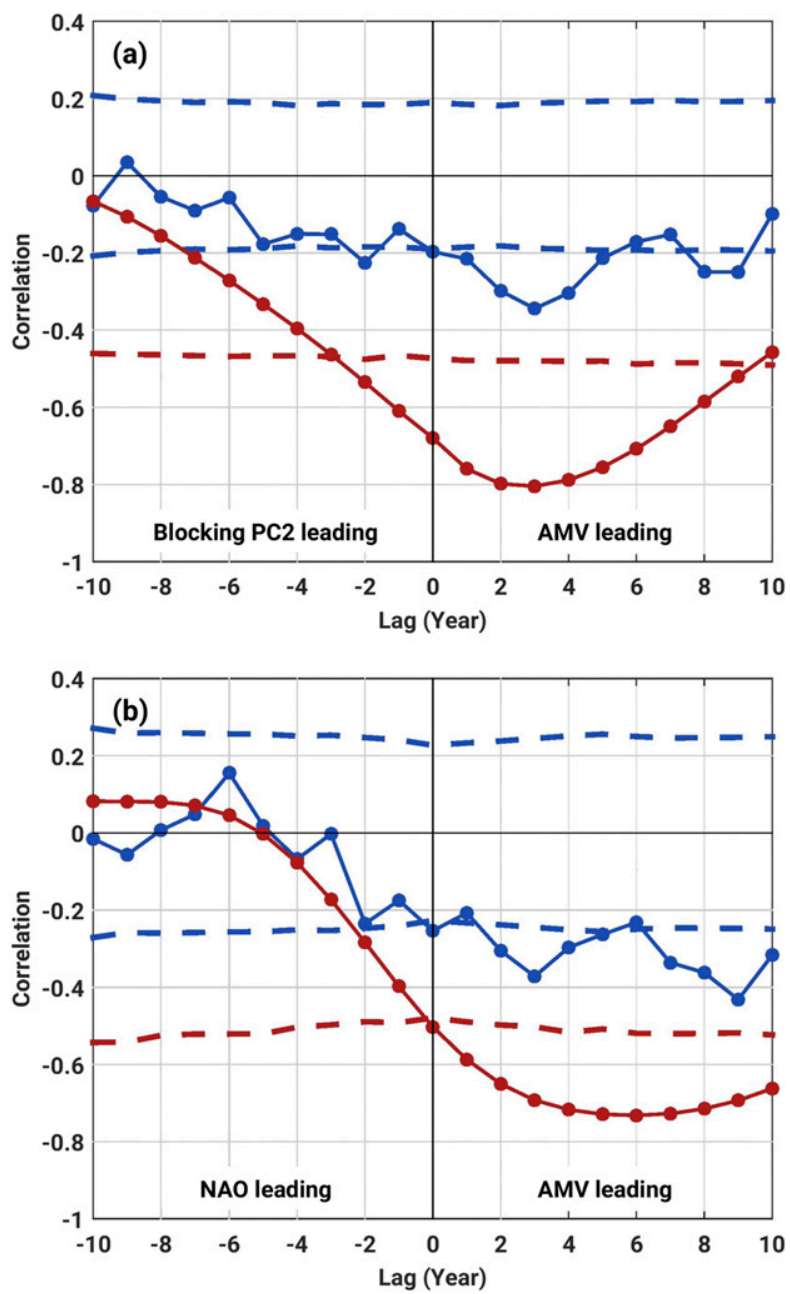

FIG. 5. Lag correlations between (a) the AMV index and PC2 of the winter number of blocking days and (b) the AMV and NAO indices. The blue (red) curves are for the correlations using the yearly values before (after) applying a 10-yr low-pass filter to both time series. The dashed curves indicate the corresponding statistical significance at the $5 \%$ level. The lag is positive (negative) when the AMV index leads (lags).

variables (e.g., blocking days) are leading or simultaneous with the AMV index, the tropical Indo-Pacific influence is not removed as these lags primarily represent the atmospheric forcing of the ocean. While removing the remote tropical Indo-Pacific influence is a standard practice in statistical studies to detect atmospheric responses to extratropical SST anomalies, our result is not very sensitive to this procedure.

The statistical significance is calculated based on nonparametric methods. For the lag correlations, the statistical significance is assessed using 10000 random permutations in the frequency domain to account for serial correlation (Ebisuzaki 1997). For the composite 

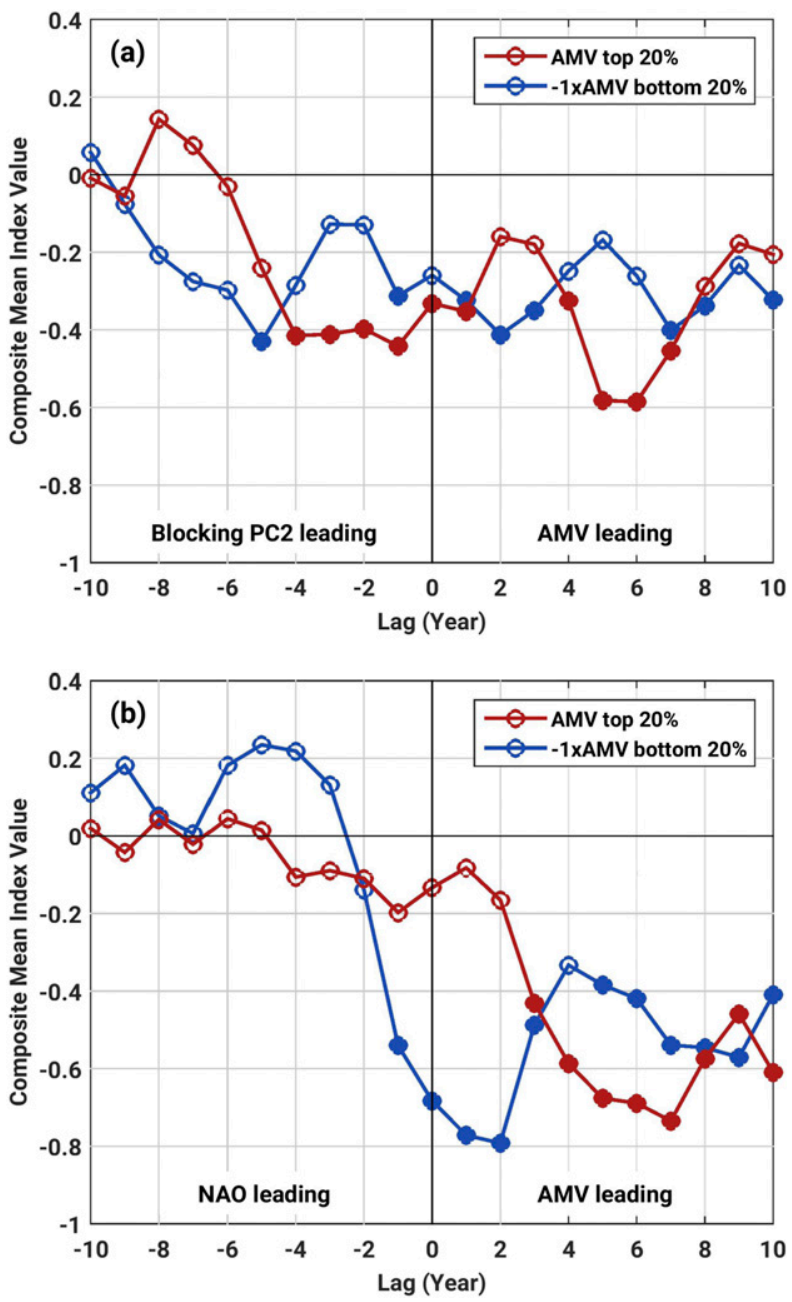

FIG. 6. Lag composite of (a) the PC2 for the number of blocking days, and (b) the NAO index based on the upper (red) and lower (blue) 20th percentile years of the 10-yr low-pass filtered AMV index, which are marked with the red and blue dots in Fig. 4b. Note that no smoothing or filtering has been applied to the PC2 and NAO time series. Filled dots indicate anomalies statistically significant at the 5\% level.

analysis, the bootstrap method with 10000 random permutations in 2-yr blocks (von Storch and Zwiers 2001 ) is used. Furthermore, field significance is assessed for the blocking days composites based on the false discovery rate (Wilks 2016).

\section{Results}

\section{a. Winter atmospheric blocking variability}

The winter climatology of the number of blocking days exhibits the maximum over the British Isles for 10-12 days out of the four winter months (Fig. 1a). In addition, enhanced blocking is found from the Azores to Scandinavia as well as over Greenland, as many previous

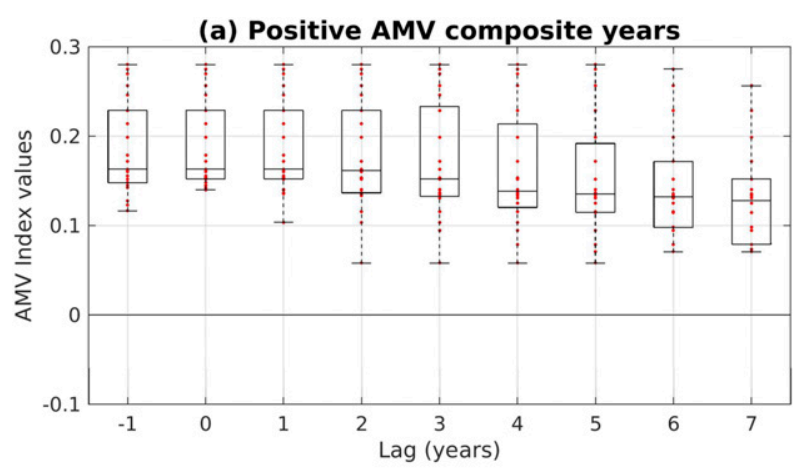

(b) Negative AMV composite years

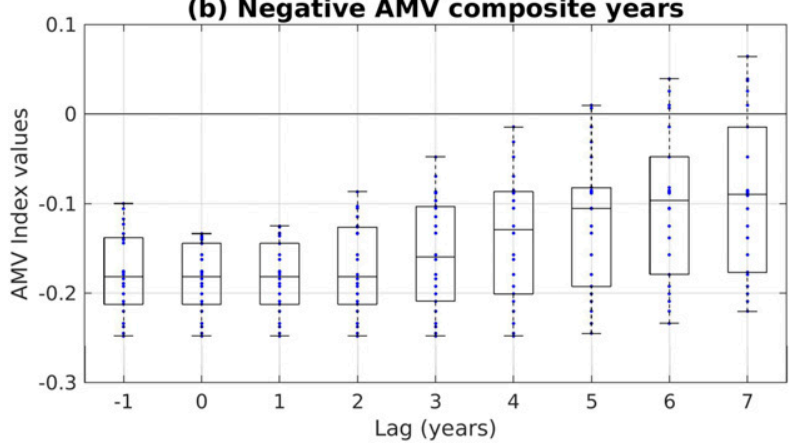

FIG. 7. Distribution of the AMV values sampled for each lagcomposite for (a) the upper and (b) lower 20th percentile years of the 10-yr low-pass filtered AMV index, which are marked with the red and blue dots in Fig. 4b. The red dots in (a) and blue dots in (b) show all the AMV values at each lag. The central mark in each box plot indicates the median value, and the bottom and top edges of the box indicate the 25 th and 75 th percentiles, respectively. The whiskers extend to the most extreme data points.

studies have shown (e.g., Scherrer et al. 2006; Häkkinen et al. 2011a; Luo et al. 2015). The interannual standard deviation shows a very similar pattern and amplitude to those of the climatological mean (Fig. 1). Hence the interannual variability primarily reflects a substantial fluctuation in the amplitude of the mean pattern rather than lateral displacement of the dominant pattern.

The leading EOF pattern exhibits the largest anomaly over the British Isles and weaker anomalies of the opposite sign over Greenland (Fig. 2a). Note that the amplitudes of anomalies are comparable to those of the interannual standard deviations, especially over the British Isles. The corresponding PC time series is dominated by interannual to decadal variability (Fig. 2c), which is well correlated with the NAO index (orange/green bars; $r=0.57$, which is statistically significant at $5 \%$ ). The power spectrum lacks power in the multidecadal and longer time scale (Fig. 3a).

The second EOF pattern shows a dipole anomaly pattern, with one sign extending from Greenland to Scandinavia and the opposite sign over the subtropics around the Azores (Fig. 2b). The amplitudes of the anomalies are 
(a) AMV lags by $1 \mathrm{yr}$

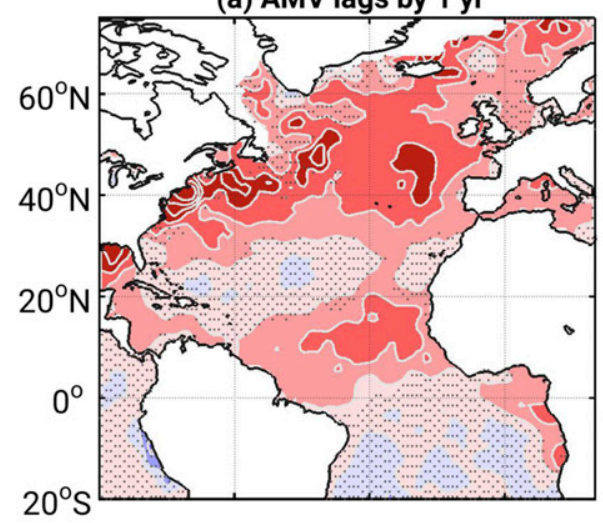

(d) AMV leads by $2 \mathrm{yr}$

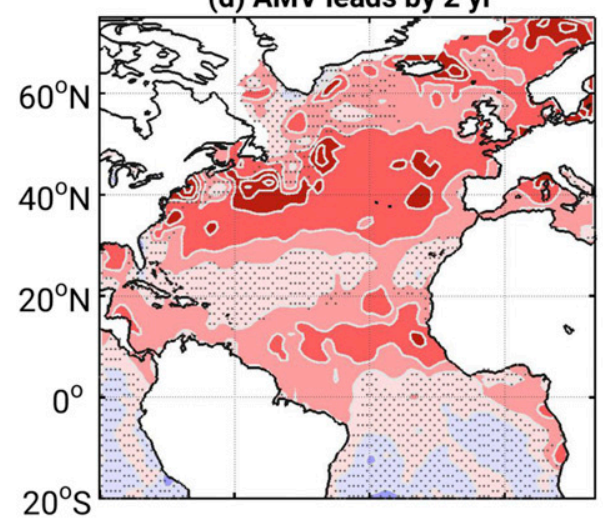

(g) AMV leads by $5 \mathrm{yr}$

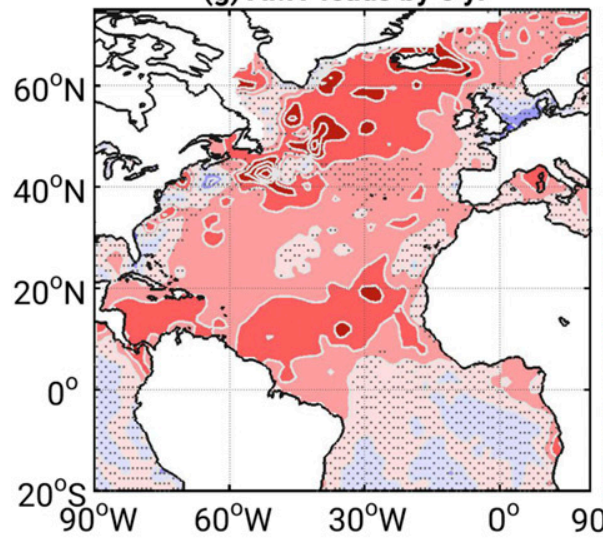

(b) AMV leads by $0 \mathrm{yr}$

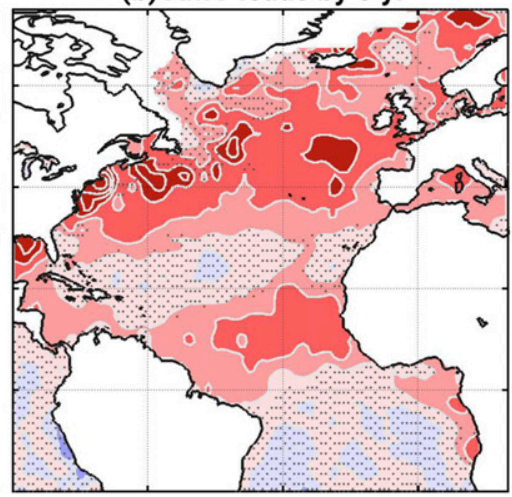

(e) AMV leads by $3 \mathrm{yr}$

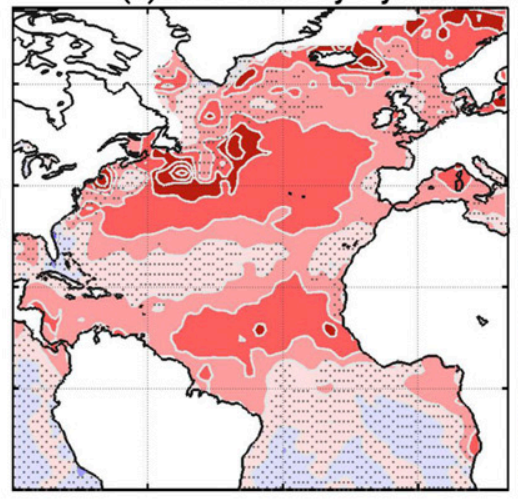

(h) AMV leads by $6 \mathrm{yr}$

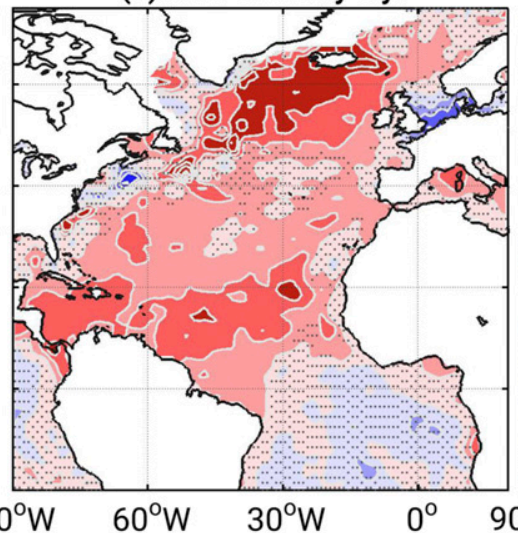

(c) AMV leads by $1 \mathrm{yr}$

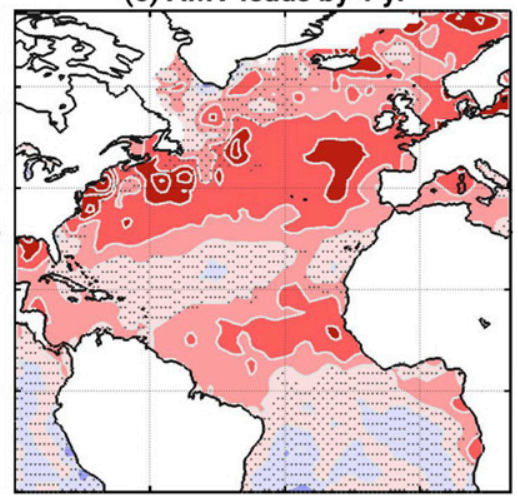

(f) AMV leads by $4 \mathrm{yr}$

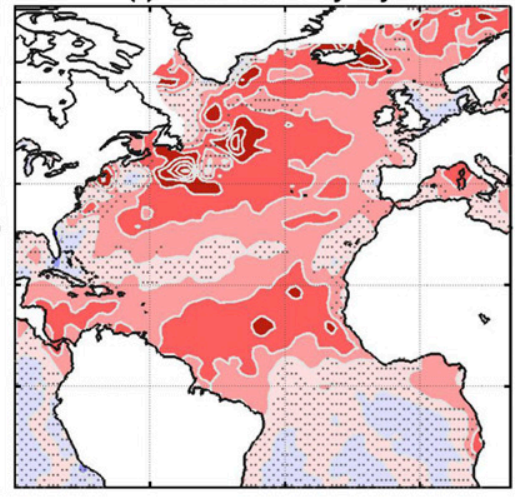

(i) AMV leads by $7 \mathrm{yr}$

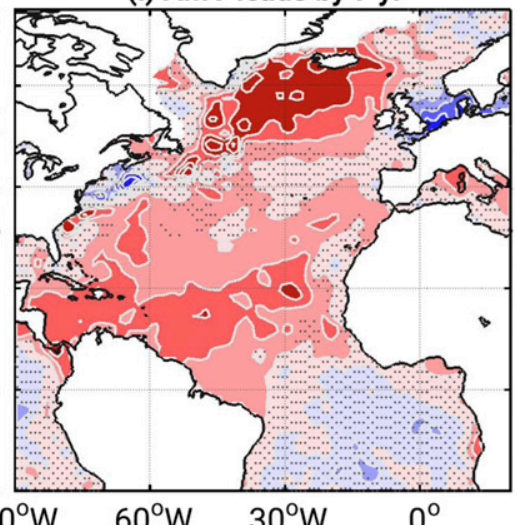

0.4

$-0.4$

$$
-0.2
$$

0

0.2

SST anomalies $\left({ }^{\circ} \mathrm{C}\right)$

FIG. 8. (a)-(i) Lag composite of the winter (December-March) SST anomalies for the upper 20th percentile years of the 10-yr low-pass filtered AMV index, which are marked with the red dots in Fig. 4b. Note that a binomial smoothing is applied to SST prior to compositing as explained in section 2c. The contour interval is $0.1^{\circ} \mathrm{C}$. Dotted regions indicate the anomalies statistically not significant at the $5 \%$ level. Influence from the tropical Indo-Pacific SST is minimized from both the SST and AMV index before compositing as explained in section 2c. 
(a) AMV lags by $1 \mathrm{yr}$

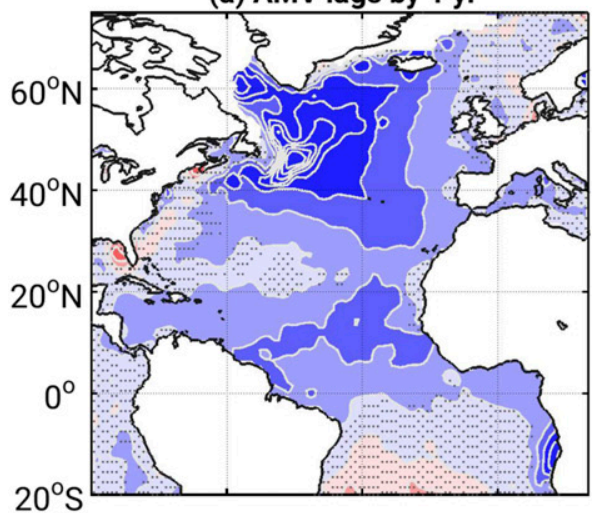

(d) AMV leads by $2 \mathrm{yr}$

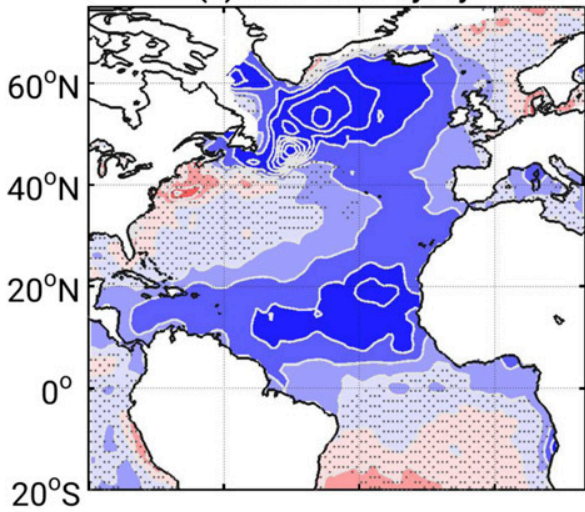

(g) AMV leads by $5 \mathrm{yr}$
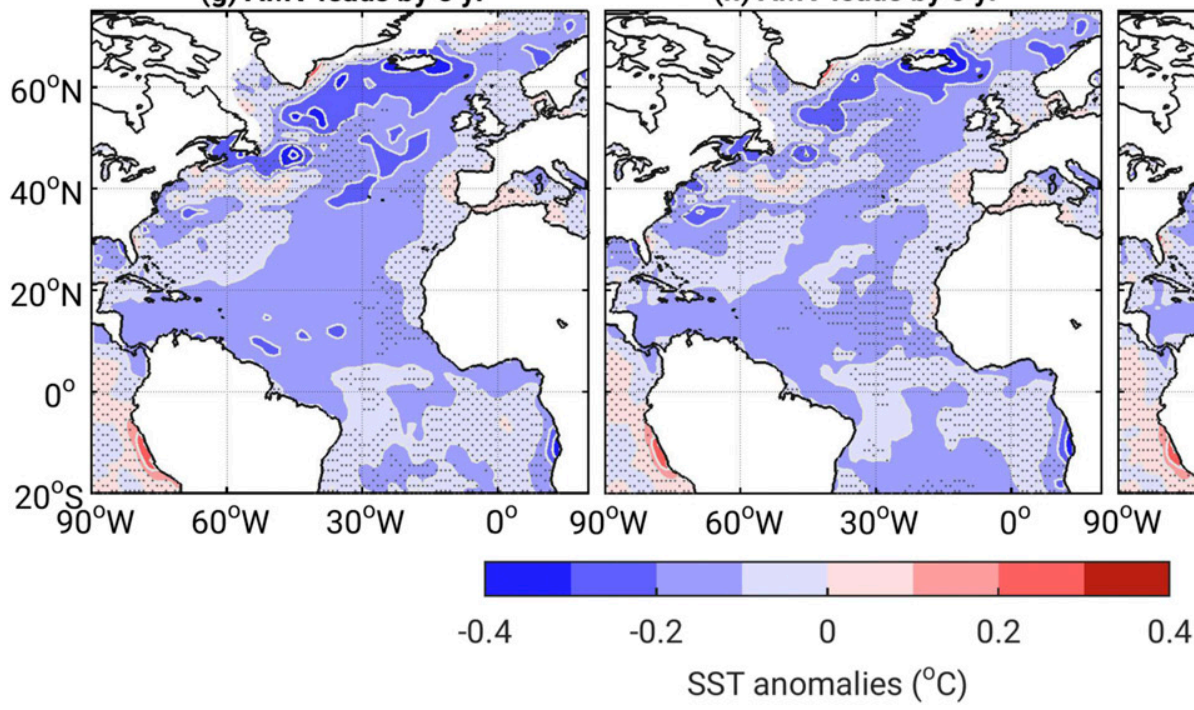

(b) AMV leads by $0 \mathrm{yr}$

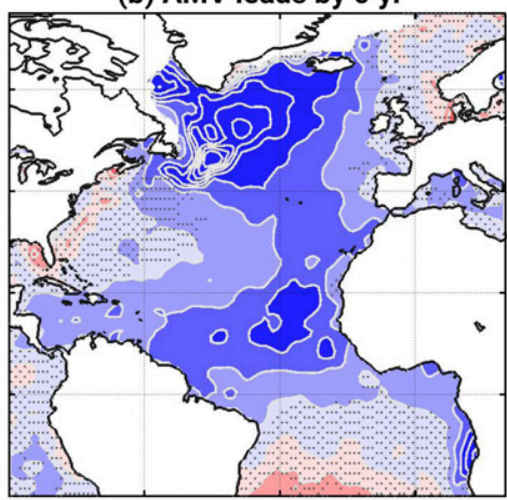

(e) AMV leads by $3 \mathrm{yr}$

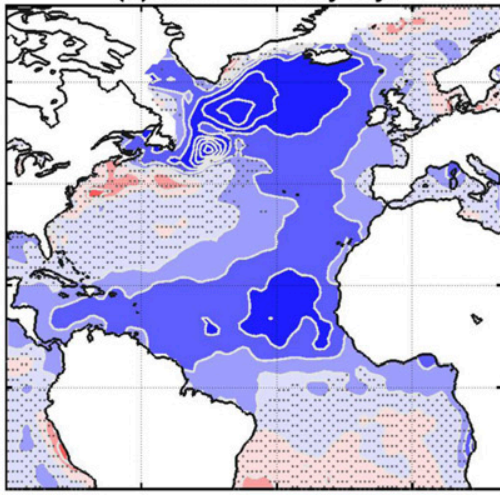

(h) AMV leads by $6 \mathrm{yr}$
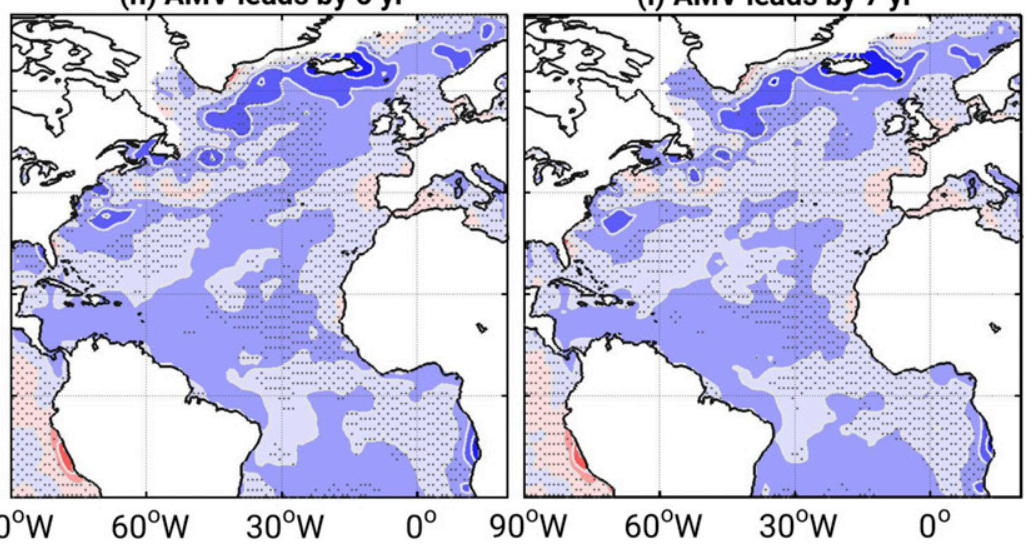

0.4 (c) AMV leads by $1 \mathrm{yr}$

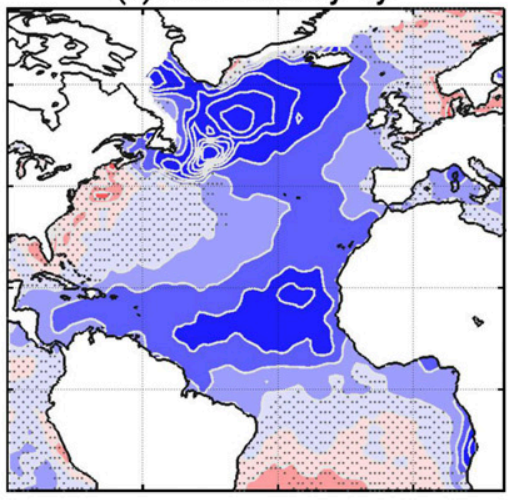

(f) AMV leads by $4 \mathrm{yr}$

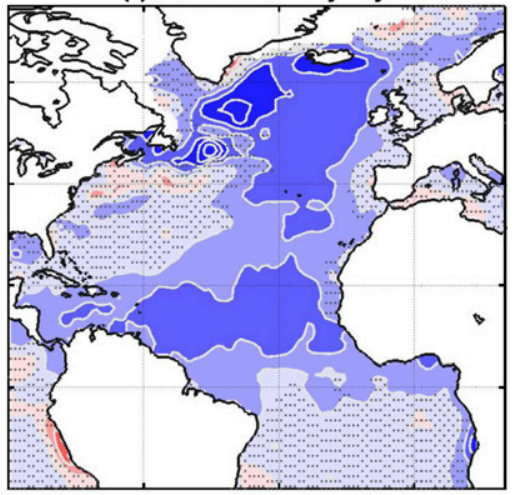

(i) AMV leads by $7 \mathrm{yr}$

FIG. 9. As in Fig. 8, but for the lower 20th percentile years of the 10-yr low-pass filtered AMV index, which are marked with the blue dots in Fig. 4b.

$30 \%-50 \%$ of the interannual standard deviations. While the second PC time series (PC2) is also significantly correlated with the NAO at $5 \%(r=0.42)$, it also exhibits enhanced multidecadal variability (Figs. $2 \mathrm{~d}$ and $3 \mathrm{~b}$ ) that is correlated with the AMV (discussed in the next section). The power spectrum for PC2 also has a significant peak around 5 years. It is unclear what process accounts for this spectral peak, but our primary focus is on the 
(a) AMV lags by $1 \mathrm{yr}$

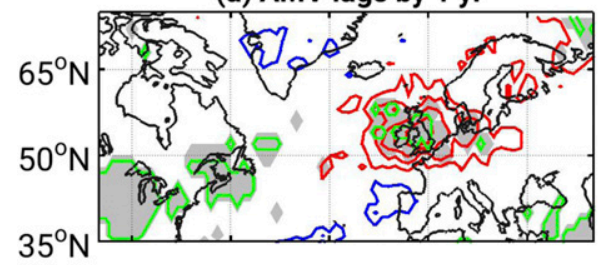

(d) AMV leads by $2 \mathrm{yr}$

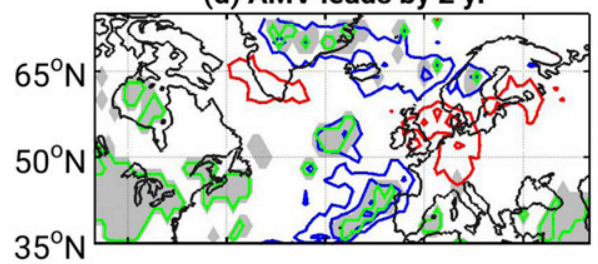

(g) AMV leads by $5 \mathrm{yr}$

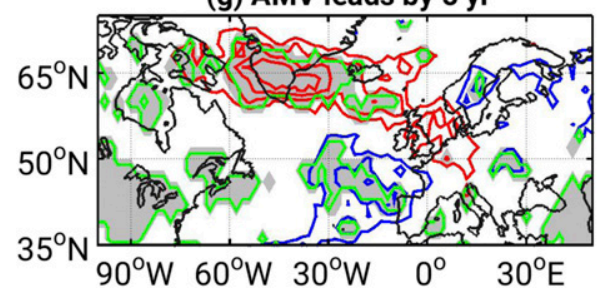

(b) AMV leads by $0 \mathrm{yr}$

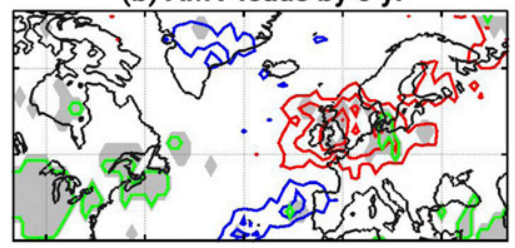

(e) AMV leads by $3 \mathrm{yr}$

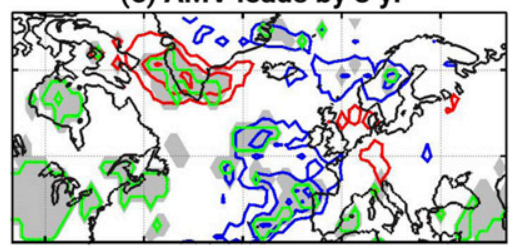

(h) AMV leads by $6 \mathrm{yr}$

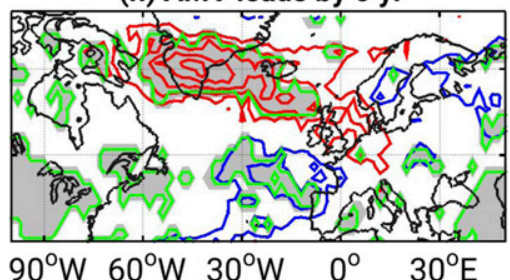

(c) AMV leads by $1 \mathrm{yr}$

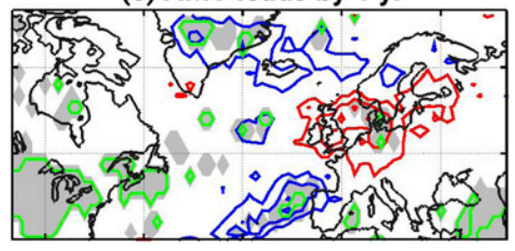

(f) AMV leads by $4 \mathrm{yr}$

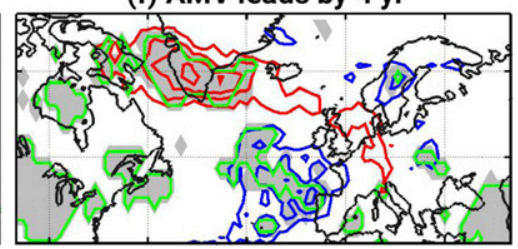

FIG. 10. (a)-(i) Lag composite of the winter (December-March) number of blocking days with respect to the upper 20th percentile years of the 10-yr low-pass filtered AMV index. Note that a binomial smoothing is applied to the number of blocking days prior to compositing as explained in section 2c. The contour interval is 1 day. Red (blue) contours are for positive (negative) anomalies. Zero contours are omitted. Gray shadings indicate anomalies that are statistically significant at the $5 \%$ level. Green contours indicate the field significance at the $10 \%$ level based on the false discovery rate. Influence from the tropical Indo-Pacific SST is minimized from both the SST and AMV index before compositing, except for in (a) and (b) as explained in section 2c.

decadal and longer time scale. This second EOF mode becomes the leading mode if a 20 -yr low-pass filter is applied first before the EOFs are calculated (not shown).

\section{b. AMV influence on blocking}

\section{1) LAG CORRELATIONS}

The AMV index and PC2 of the winter blocking days clearly covary on decadal to multidecadal time scales (Fig. 4a). The simultaneous correlation between the two is -0.68 , when a $10-y r$ low-pass filter is applied to both time series (Fig. 5a). More importantly, their lag correlation is highly asymmetric between the positive and negative lags; the maximum correlation is found when AMV leads the blocking PC2 by $2-4$ years, whereas there is no significant correlation when the blocking PC2 leads the AMV (Fig. 5a). This lead/lag relationship holds regardless whether the 10-yr low-pass filter is applied to both time series or not, although the asymmetry does become somewhat more pronounced and the peak becomes broader due to the filtering when the low-pass filter is applied (Fig. 5a). Note that a similar asymmetry in the correlation between the AMV and NAO time series has been reported by Peings and Magnusdottir (2014) and Gastineau and Frankignoul (2015), which is shown in Fig. 5b. Furthermore, the power spectra of the blocking PC2, AMV, and NAO commonly exhibit enhanced power in the multidecadal and longer time scales (i.e., > $>50$ years; Figs. 3b-d), although the multidecadal peak in the PC2 is statistically not different from the white noise null hypothesis at the $5 \%$ level. On the other hand, PC1 has greater power than PC2 at decadal time scales (10-20 years; Figs. 3a,b).

\section{2) SST EVOLUTION}

To investigate the mechanism for the link between the AMV and blocking variability associated with the second EOF, we will use lag-composite analyses of several variables based on the top and bottom 20 percentile years, respectively, from the 10-yr low-pass filtered AMV index (Fig. 4b). When a lag composite is used, the relationship found above from the lag correlations turns out to be very different between the warm and cold AMV years, in particular for the NAO, but also for PC2 (Fig. 6). The lag 
(a) AMV lags by $1 \mathrm{yr}$

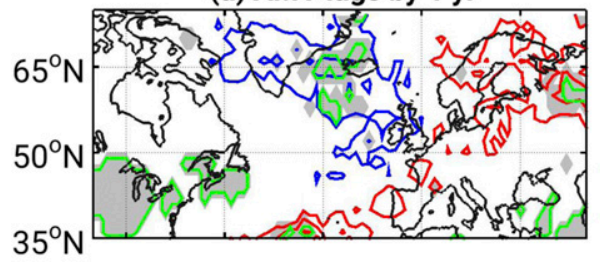

(d) AMV leads by $2 \mathrm{yr}$

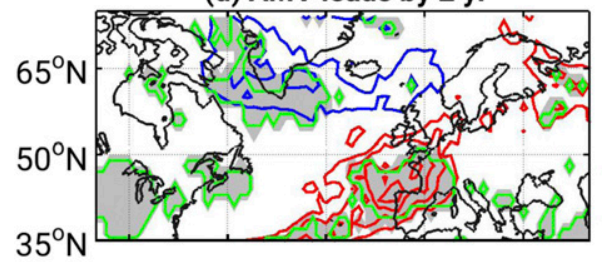

(g) AMV leads by $5 \mathrm{yr}$

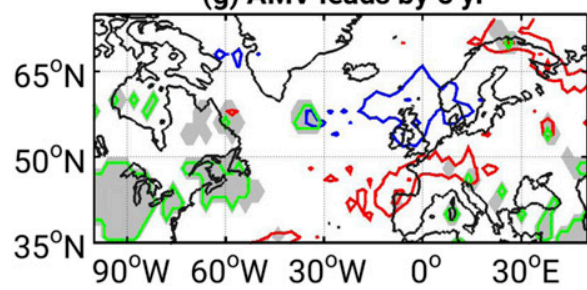

(b) AMV leads by 0 yr

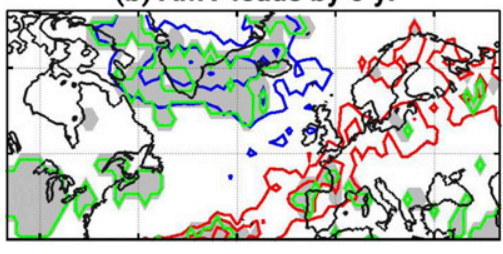

(e) AMV leads by 3 yr

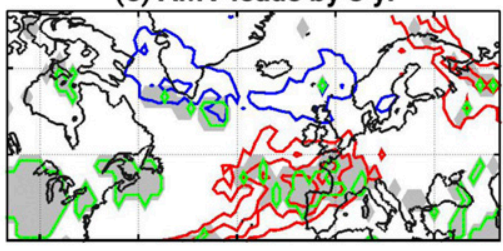

(h) AMV leads by 6 yr

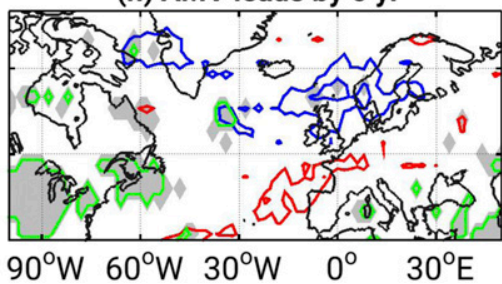

(c) AMV leads by $1 \mathrm{yr}$

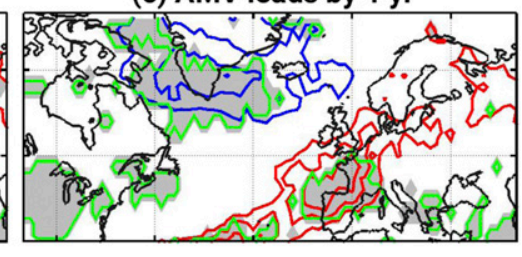

(f) AMV leads by $4 \mathrm{yr}$

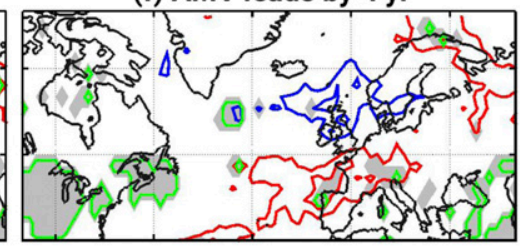

FIG. 11. As in Fig. 10, but for the lower 20th percentile years of the 10-yr low-pass filtered AMV index.

composites for the cold AMV years show the peaks around a lag $=2$ years for both PC2 and NAO composites (blue curves in Fig. 6), while the warm AMV year composite shows the peaks at much longer lag around 5-7 years (red curves in Fig. 6). Furthermore (as shown in Figs. 8-11) the evolutions of blocking and SST following the warm AMV years are very different from those following the cold AMV years. Given the large difference between the warm and cold phases of AMV, composite analysis is more appropriate to use than regressions. However, we note that not all the composite spatial patterns for individual lags are independent as they are based on the 10-yr low-pass filtered AMV index. Therefore, only the overall evolution of the spatial patterns is emphasized here. Figure 7 shows what AMV states are sampled for each lag composite. While the ranges of sampled AMV states (i.e., the distance between the 25th and 75th percentiles) are slowly growing with larger lags as expected, the median values of the sampled AMV states are decreased by only $20 \%$ between lag 0 and +7 for the warm AMV years (Fig. 7a). For the cold AMV years, only $12 \%$ change in median values is found between lag 0 and +3 , when the significant blocking responses are found below (Fig. 11). Therefore, the lag composites imply that the time evolution of AMV states is overall similar to those sampled at lag 0 .
The evolution of the warm SST anomalies associated with the upper 20th percentile years of the 10-yr low-pass filtered AMV index exhibits the warmest anomalies along the North Atlantic Current near the Tail of the Grand Banks initially when the warm AMV leads by 0 and 1 year (Figs. 8b,c). Those anomalies gradually intensify out to lag $=5$ years (Figs. 8d-g). Subsequently, the warmest anomalies are found in the subpolar gyre at lag $=6-7$ years (Figs. 8h,i). At the same time, a small patch of cold SST anomalies develops in the northern recirculation gyre to the north of the Gulf Stream. Overall, the warmest anomalies are found near the boundary between the subtropical and subpolar gyres, the so-called intergyre gyre region (Marshall et al. 2001), until lag $=4-5$ years, and then in the subpolar gyre in the subsequent years.

On the other hand, the composite for the cold AMV years reveals a very different evolution of the cold SST anomalies (Fig. 9). The initial SST anomaly patterns for the years when the cold AMV lags by 1 year to leading by 1 year exhibit a tripole pattern with the strongest anomalies in the subpolar gyre, similar to the previously reported AMV patterns (Ting et al. 2009; Guan and Nigam 2009). The coldest anomalies are localized along the North Atlantic Current near the Flemish Cap $\left(\sim 47^{\circ} \mathrm{N}, 45^{\circ} \mathrm{W}\right)$ and the warmest anomalies near the Gulf Stream when the cold AMV leads by 2 years (Figs. 9c-e). Subsequently, 

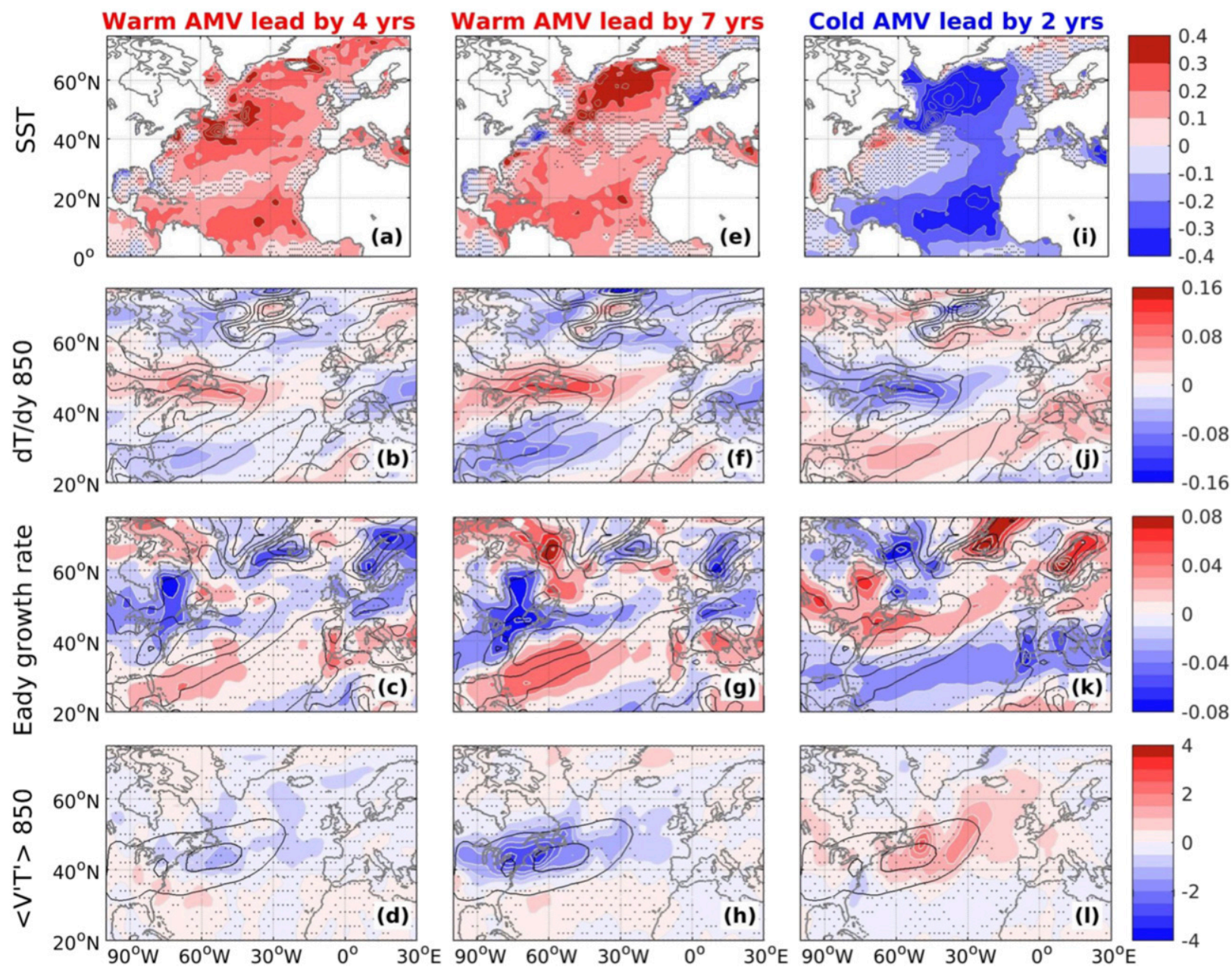

FIG. 12. Lag composite of the winter (December-March) (a),(e),(i) SST, (b),(f),(j) meridional temperature gradient at $850 \mathrm{hPa}$, (c),(g),(k) maximum Eady growth rate at $850 \mathrm{hPa}$, and (d),(h),(i) $v^{\prime} T^{\prime}$ at $850 \mathrm{hPa}$. Note that a binomial smoothing is applied to these SST and atmospheric variables prior to compositing as explained in section $2 \mathrm{c}$. The composite is calculated based on the 10-yr low-pass filtered AMV index when (left) the top 20th percentile years leads by 4 years, (center) the top 20th percentile years leads by 7 years, and (right) the bottom 20th percentile years leads by 2 years. Dotted regions indicate the anomalies statistically not significant at the $5 \%$ level. Black contours are for the climatological mean. Contour intervals for anomalies (mean) are $0.1^{\circ} \mathrm{C}, 0.02(0.3) \mathrm{K} \mathrm{m}^{-1}, 0.02(0.2) \mathrm{day}^{-1}$, and 0.5 (6) $\mathrm{K} \mathrm{m} \mathrm{s}^{-1}$, respectively. Influence from the tropical Indo-Pacific SST is minimized as explained in section $2 \mathrm{c}$.

the cold AMV SST anomalies diminish much more rapidly compared to the warm AMV SST anomalies.

\section{3) BLOCKING EVOLUTION ASSOCIATED WITH AMV}

Similar to the SST anomalies, the blocking day anomaly composites also exhibit very different evolutions between the warm and cold AMV years. For the warm AMV index composite, positive blocking day anomalies are centered over the British Isles with the maximum amplitude of 4 days at one year prior to the AMV composite years (Fig. 10a). A similar pattern, but with slightly weaker amplitude, is found at zero lag, which further weakens when the warm AMV leads by 1 year (Figs. 10b,c). This blocking anomaly pattern is associated with the eastern Atlantic pattern, which has been suggested to drive the AMV SST pattern (Häkkinen et al. 2011a, 2011b). Note that the field significance test (green contours) based on the false discovery rate (Wilks 2016) indicates that the anomalies at these short lags are marginally significant.

Another anomaly pattern, which projects well on the EOF2 pattern and is more significant based on the field significance, slowly emerges in the blocking composites starting when the warm AMV leads by 3 years (Figs. 10e-i). This anomaly pattern exhibits more frequent blocking over Greenland and reduced blocking days over the Azores following the warm AMV years. Note that the amplitudes of the anomalies over Greenland are comparable to the 

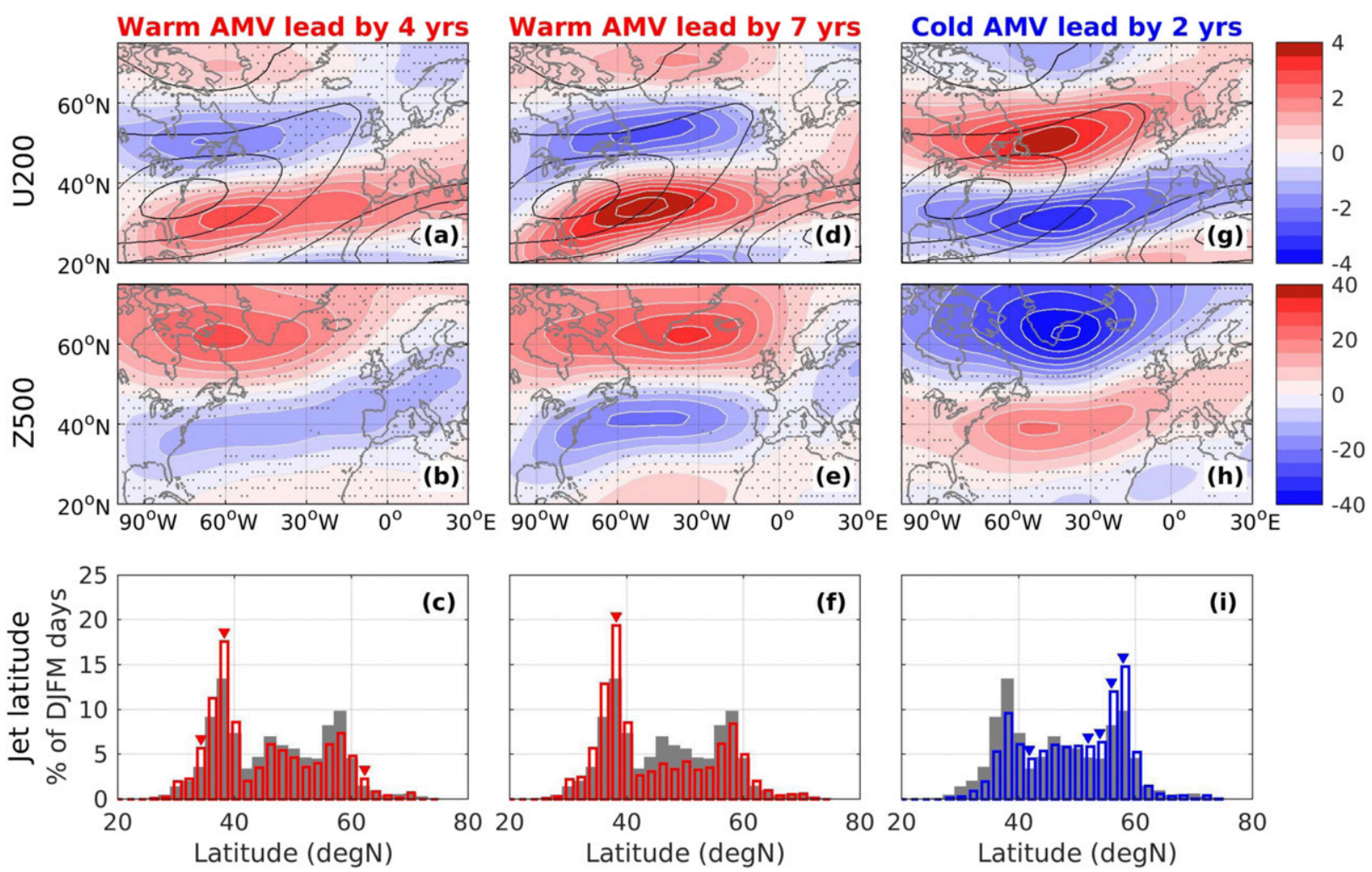

FIG. 13. As in Fig. 12, but for (a),(d),(g) the zonal wind speed at $200 \mathrm{hPa}$,(b),(e),(h) geopotential height at $500 \mathrm{hPa}$, and (c),(f),(i) daily jet latitude histogram. Contour intervals for anomalies (mean) are 0.5 (10) $\mathrm{m} \mathrm{s}^{-1}$ and $5 \mathrm{~m}$, respectively. For the histograms in (c), (f), and (i), the gray bars are for all the years, while red and blue are for only the composited AMV years. Inverse triangles indicate statistically significant anomalies at the $5 \%$ level.

interannual standard deviation (Fig. 1b). On the other hand, a similar pattern with the opposite sign also appears in the cold AMV year composite, but for much shorter lags with the maximum amplitudes when the cold AMV leads by 2 years (Fig. 11), which is consistent with the evolution of the cold SST anomalies (Fig. 9). We will further explore in the following section how the AMV SST anomalies drive this blocking day anomaly pattern with a dipole between the regions over Greenland and the Azores.

\section{c. Mechanistic link from the AMV to blocking variability}

\section{1) STORM TRACK, JET, AND CIRCULATION ANOMALIES FOLLOWING THE WARM AMV}

To establish a mechanistic link from the SST to the blocking day anomalies, we examine the composite anomalies of various atmospheric variables associated with the storm track and eddy-driven jet. For display purposes, only a few lags are selected and shown in Figs. 12 and 13. The anomalies following the warm AMV years by 4 years (the first column in Figs. 12 and 13) reveal an emerging anomalous atmospheric circulation associated with the early developing stage of the dipole blocking anomaly pattern (Fig. 10f).

The climatological mean of the meridional temperature gradient at $850 \mathrm{hPa}$ exhibits the minimum (as in general $d T / d y<0$ ) around $40^{\circ} \mathrm{N}$ near the Gulf Stream (the black contours in Fig. 12b). The anomalies have the meridional dipole pattern that straddles the minimum in the climatological mean (Fig. 12b). The maximum Eady growth rate at $850 \mathrm{hPa}$ exhibits similar patterns, but with opposite signs (Fig. 12c). In particular, the northern anomalies around $40^{\circ}-50^{\circ} \mathrm{N}$ are dominant in the earlier lags. This suggests an overall weakening and slight southward migration of the maximum baroclinicity region following the warm AMV primarily due to the changes in the meridional temperature gradient over the warmest SST anomalies near the Grand Banks (Fig. 12a). Consistently, the meridional synoptic transient eddy heat flux at $850 \mathrm{hPa}$ becomes overall weaker and slightly shifts equatorward (Fig. 12d).

Novak et al. (2015) showed that changes in the meridional synoptic transient eddy heat flux near the Gulf Stream in the lower troposphere have a downstream barotropic effect that results in shifts in the eddy-driven jet latitude. In particular, they found the weaker meridional 

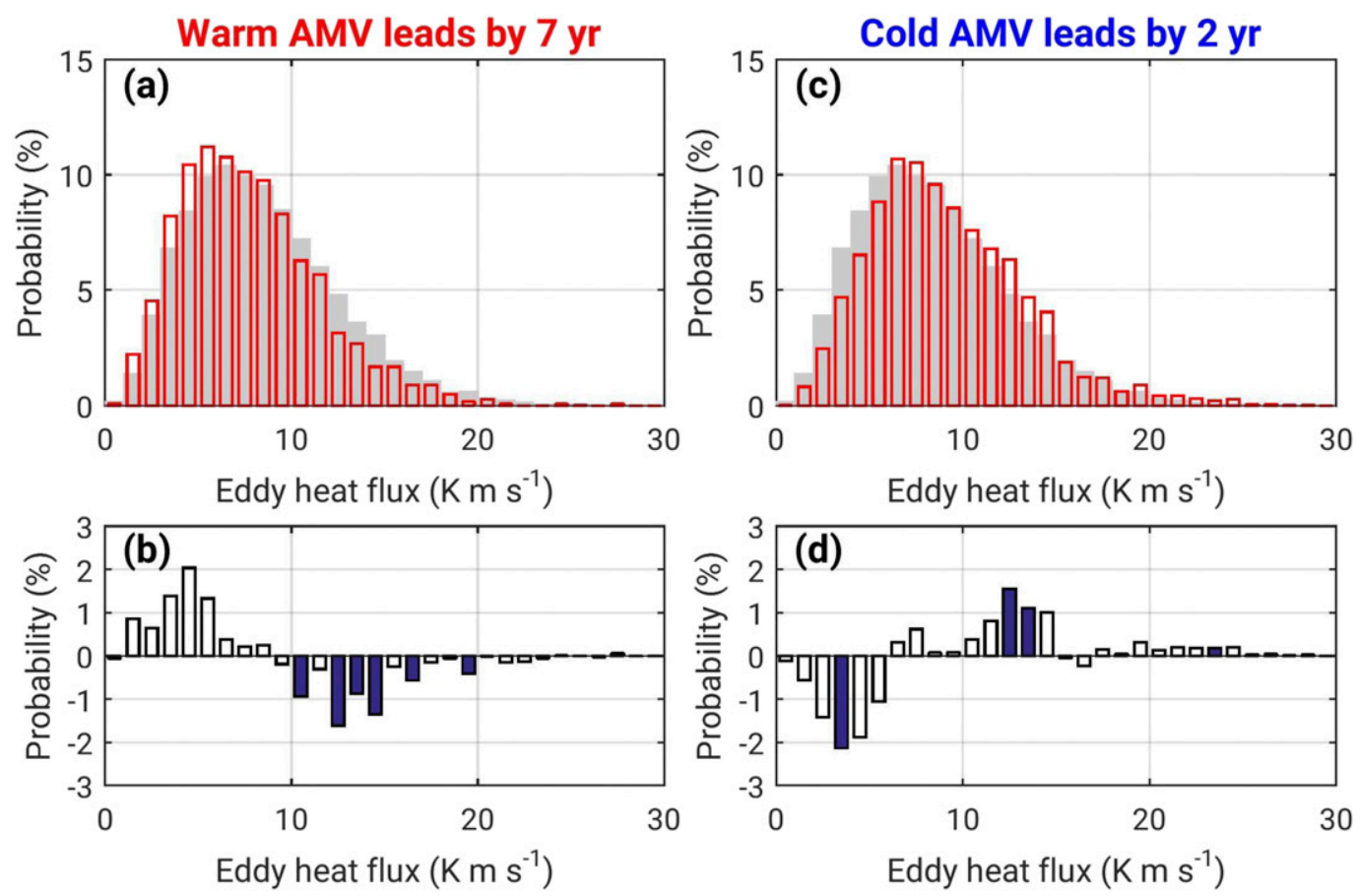

FIG. 14. (a) Histogram of daily low-frequency meridional transient eddy heat flux $\left(\overline{v^{\prime} T^{\prime}}\right)$ at $850 \mathrm{hPa}$ averaged over $30^{\circ}-50^{\circ} \mathrm{N}, 40^{\circ}-70^{\circ} \mathrm{W}$ in winter (December-March) for the years following the top 20th percentile years of the 10-yr low-pass filtered AMV index by 7 years (red bars). The gray bars are climatological distribution for winter from all the years. (b) The difference between the two distributions shown in (a). The filled bars indicate the differences statistically significant at the $5 \%$ level. (c),(d) As in (a) and (b), but for the years following the bottom 20 th percentile years of the 10 -yr low-pass filtered AMV index by 2 years.

synoptic transient eddy heat flux results in dominant cyclonic wave breaking on the northern flank of the jet and an equatorward shift of the jet. O'Reilly et al. (2016b, 2017a) also found this relationship in their AGCM experiment. In addition to the seasonal mean storm track anomalies (Figs. 12d,h), we also examine the daily lowfrequency transient eddy heat flux (defined by 9-day moving average) over the maximum storm track region $\left(30^{\circ}-50^{\circ} \mathrm{N}, 40^{\circ}-70^{\circ} \mathrm{W}\right)$ following Novak et al. (2015) and O'Reilly et al. (2017a). The distribution of daily eddy heat flux following the warm AMV exhibits an overall shift toward the weaker heat flux compared to the climatological mean distribution (Fig. 14a). In particular, the number of strong heat flux events in the upper $25 \%$ of the climatological distribution $\left(>10 \mathrm{~K} \mathrm{~m} \mathrm{~s}^{-1}\right)$ is significantly decreased, while the number of weak events in the bottom $25 \%\left(<5 \mathrm{~K} \mathrm{~m} \mathrm{~s}^{-1}\right)$ is increased (Fig. 14b).

Consistent with the mechanism by Novak et al. (2015), we find in our analysis that the eddy-driven jet also migrates equatorward (Fig. 13). The shift of jet is apparent in both the anomalies of the seasonal mean jet shown by the 200-hPa zonal wind (Fig. 13a) and the distribution of the daily eddy-driven jet latitude (Fig. 13c). The more southerly jet would accompany enhanced Rossby wave breaking to the north of the jet and result in more frequent blocking over Greenland and less over the Azores. This is consistent with the dipole blocking anomaly pattern shown in Fig. 10f. The Z500 anomalies show high pressure anomalies over the subpolar North Atlantic and low pressure anomalies over the subtropics.

These anomalies gradually amplify and reach a mature phase as shown for the composites when the warm AMV leads by 7 years (second columns in Figs. 12 and 13), which is consistent with the evolution of the blocking anomalies (Fig. 10). In particular, the Z500 anomalies exhibit the negative phase of the NAO. Positive feedback between the enhanced Rossby wave breaking and resulting blocking to the north of the jet and southerly displacement of the jet would support the amplification of these anomalies by reinforcing each other (cf. Michel and Rivière 2011).

\section{2) TuRbulent heAt FluX ANOMALIES}

To make a more explicit link between the SST anomalies and the atmospheric responses, the turbulent surface heat flux anomalies are examined. The turbulent heat flux anomalies are affected by influence from both the ocean and atmospheric variability. The latter includes the atmospheric circulation anomalies in response to the AMV 

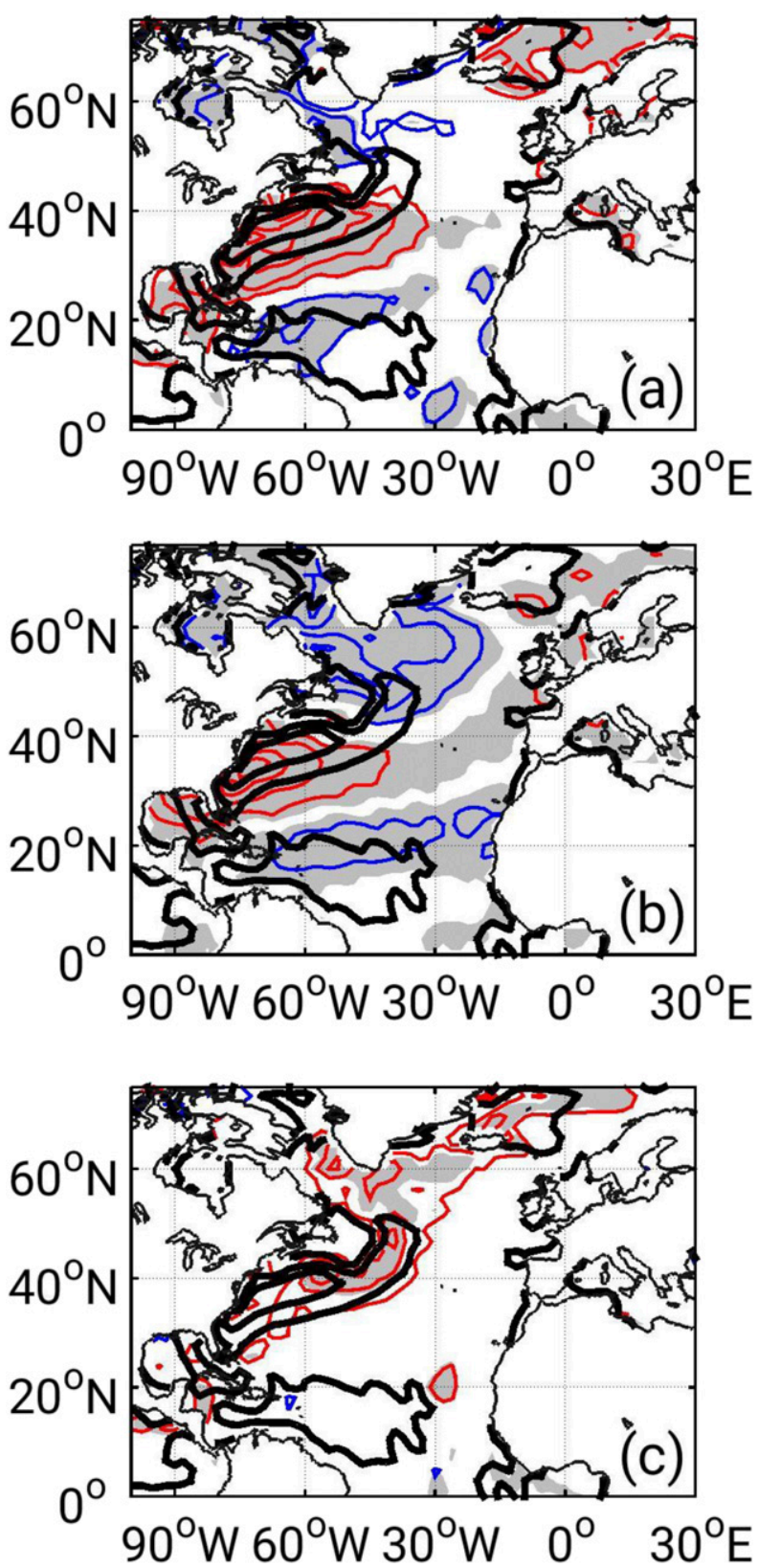

FIG. 15. Decomposition of the winter (December-March) turbulent surface heat flux anomalies associated with the top 20th percentile years of the 10-yr low-pass filtered AMV index when AMV index leads by 4 years. (a) Total anomalies, which is the lag composite as in Figs. 8-13. Note that a binomial smoothing is applied to the heat flux prior to compositing as explained in section 2c. (b) Anomalies driven by the anomalous atmospheric circulation response to the AMV. This component is calculated as the regression on the time series associated with the $500-\mathrm{hPa}$ geopotential height (Z500) composite anomalies at the same lag. The Z500 time series is calculated by projecting the full Z500 field to the anomalous Z500 composite pattern (Fig. 13b). The domain used for the $\mathrm{Z} 500$ projection is $20^{\circ}-75^{\circ} \mathrm{N}, 90^{\circ} \mathrm{W}-30^{\circ} \mathrm{E}$. (c) Anomalies directly driven by the ocean variability associated with AMV. This component is calculated as the difference between the above two components, i.e., (a) minus (b). The positive heat flux is described in the previous section, which are confounded with the former (i.e., direct influence from AMV). Therefore, total turbulent heat flux anomalies (Fig. 15a) are decomposed into the part that is driven by the anomalous atmospheric circulation associated with the AMV (Fig. 15b) and the part that is directly driven by the AMV (Fig. 15c), which is inferred as the residual. This decomposition is necessary because the part that is driven by the atmospheric circulation response is quickly established and often dominates the total anomalies (e.g., Gastineau and Frankignoul 2012).

The component of the turbulent surface heat flux anomalies that is directly responding to the warm SST anomalies when the warm AMV leads by 4 years exhibits significant positive (i.e., upward) anomalies over the western subpolar gyre with a maximum from the Tail of the Grand Banks to the Flemish Cap (Fig. 15c). These AMV-driven positive heat flux anomalies are collocated with the maximum warm SST anomalies when the warm AMV leads by 4 years (Fig. 12a). Therefore, the heat flux anomalies are damping the SST anomalies instead of driving them (Gulev et al. 2013; O'Reilly et al. 2016a; Zhang et al. 2016). Recall that the region of the maximum upward heat flux and SST anomalies also coincides with the region where the largest meridional temperature gradient anomaly at $850 \mathrm{hPa}$ is found at the corresponding lag (Fig. 12b).

On the other hand, we find very weak heat flux anomalies in the tropics that are directly responding to the warm AMV SST anomalies (Fig. 15c), which suggests a primary role for the extratropical part of the AMV SST anomalies in driving atmospheric circulation response to AMV (Peings and Magnusdottir 2014, 2016; Gastineau et al. 2016).

\section{3) COMPARISON BETWEen THE WARM AND COLD PHASE OF THE AMV}

The atmospheric anomalies when the warm AMV leads by 7 years are very similar to the corresponding anomalies when the cold AMV leads by 2 years, except that the sign of the anomaly is reversed (last columns in Figs. 12 and 13). This is consistent with the corresponding blocking anomalies for the warm and cold AMV (Figs. 10i and 11d). Therefore, different evolutions of the warm and cold SST anomalies (Figs. 8 and 9)

for transferring heat from the ocean to the atmosphere. Red (blue) contours are for positive (negative) anomalies. Zero contours are omitted. Gray shading indicates anomalies statistically significant at the $5 \%$ level. Thick black contours are for the climatological mean. Contour intervals for anomalies and mean are 5 and $100 \mathrm{~W} \mathrm{~m}^{-2}$, respectively. 

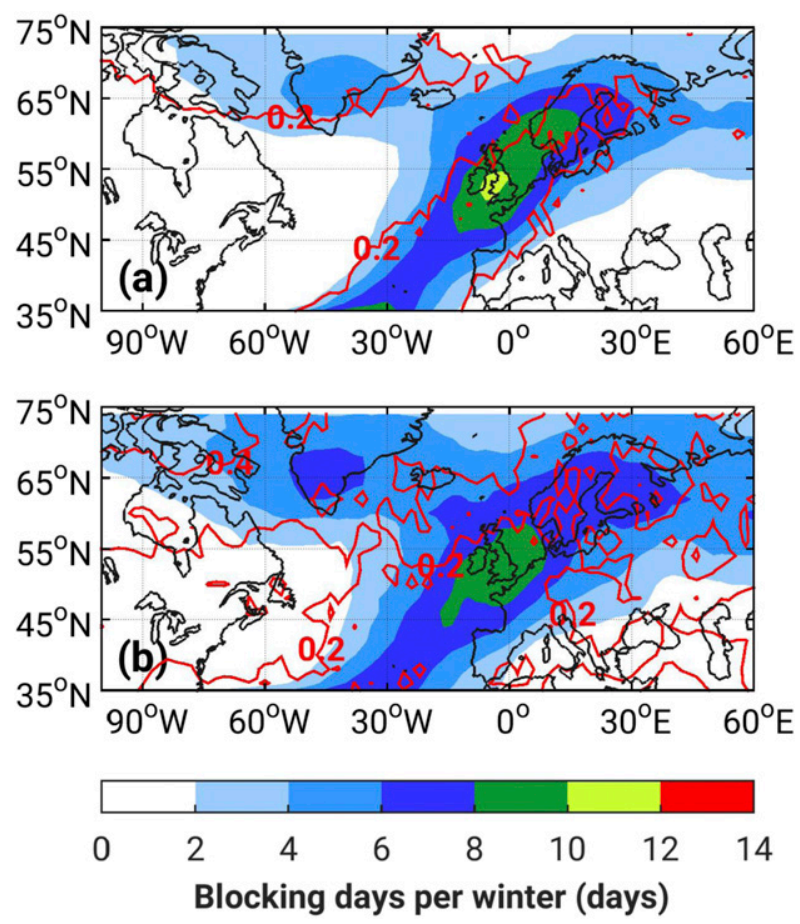

FIG. A1. Ensemble average of (a) the climatological mean and (b) interannual standard deviation of the winter (December-March) number of blocking days for 1901-2010 based on the daily Z500 from each of the 56 ensemble members of the 20CR. The ensemble standard deviation is indicated with the red contours (days).

are likely responsible for the distinct timing of the responses in the two cases. Although the SST anomalies when the warm AMV leads by 7 years and those when the cold AMV leads by 2 years do not exhibit exactly the same spatial patterns with the opposite sign (Figs. 12e,i), the common ingredients between the two SST anomaly patterns are the maximum anomalies in the subpolar gyre, weaker tropical anomalies, and the weak opposite anomalies in the northern recirculation gyre of the Gulf Stream. Especially, the SST anomalies in the western subpolar gyre in both cases lead to damping of SST anomalies by the turbulent heat fluxes for both the warm AMV (at lag $=4-7$ years; Fig. 15c) and cold AMV (at lag $=-1$ to 2 years; not shown). Furthermore, the daily low-frequency transient eddy heat fluxes exhibit the opposite anomalies in the two cases, namely more (less) frequent intense eddy heat flux events for the cold (warm) AMV case (Fig. 14), which drives northward (southward) shift of the eddy-driven jet (Figs. 13d,g; Novak et al. 2015; O'Reilly et al. 2017a).

\section{4) SuMmary OF THE MECHANISTIC LINK}

The following mechanistic link between AMV and blocking emerges from the above results. The warm SST anomalies in the western subpolar gyre associated with the AMV (presumably driven by changes in the ocean circulation) are damped by the surface heat flux (Gulev et al. 2013; O'Reilly et al. 2016a; Zhang et al. 2016), which in turn provides anomalous heating to the lower troposphere. This then reduces the meridional temperature gradient and thus weakens overall baroclinicity and meridional synoptic transient eddy heat flux in the lower troposphere in the western North Atlantic near the maximum mean storm track. The weakened meridional synoptic transient eddy heat flux further results in the dominance of cyclonic wave breaking, and hence southward displacement of the eddy-driven jet, with the jet becoming more zonal (Novak et al. 2015; O'Reilly et al. 2017a). With the southerly jet position, the Rossby wave breaking is increasingly more favored on the poleward flank of the jet, which results in more frequent blocking over Greenland and less over the Azores (Woollings et al. 2008, 2010; Rivière 2009; Barnes and Hartmann 2010; Davini and Cagnazzo 2014; Kwon et al. 2018). As a result, the negative phase of the NAO becomes a dominant pattern following the warm AMV. The same link seems to be valid for the cold AMV anomalies but with a shorter lag.

\section{Summary and discussion}

Influence of multidecadal North Atlantic SST variability, which is represented by the AMV, on the winter (December-March) atmospheric blocking variability over the North Atlantic sector is examined based on the NOAA Twentieth Century Reanalysis and ERA-20C for 1901-2010. The second EOF mode of the winter blocking frequency, showing the oppositely signed anomalies over Greenland and the Azores, exhibits a dominant multidecadal variability, while the first mode is dominated by higher-frequency variability. The second mode is significantly correlated with the AMV with the maximum correlation found when the AMV leads blocking by several years.

Composite analyses suggest that the lag of several years is due to the slow evolution of the AMV SST anomalies, which is likely driven by the ocean circulation. The lag of several years is too long to be considered as the atmospheric response time to the SST anomalies. The spatial pattern of SST anomalies evolves continuously associated with the AMV, even when the 10-yr low-pass filter is applied. Therefore, the lag can be interpreted as the time for the SST anomalies to evolve into a pattern that is optimal to induce the maximum response of the atmospheric circulation, although our analysis method does not specifically seek an optimal pattern. The ocean and atmosphere, of course, continuously interact and evolve together during this time. 

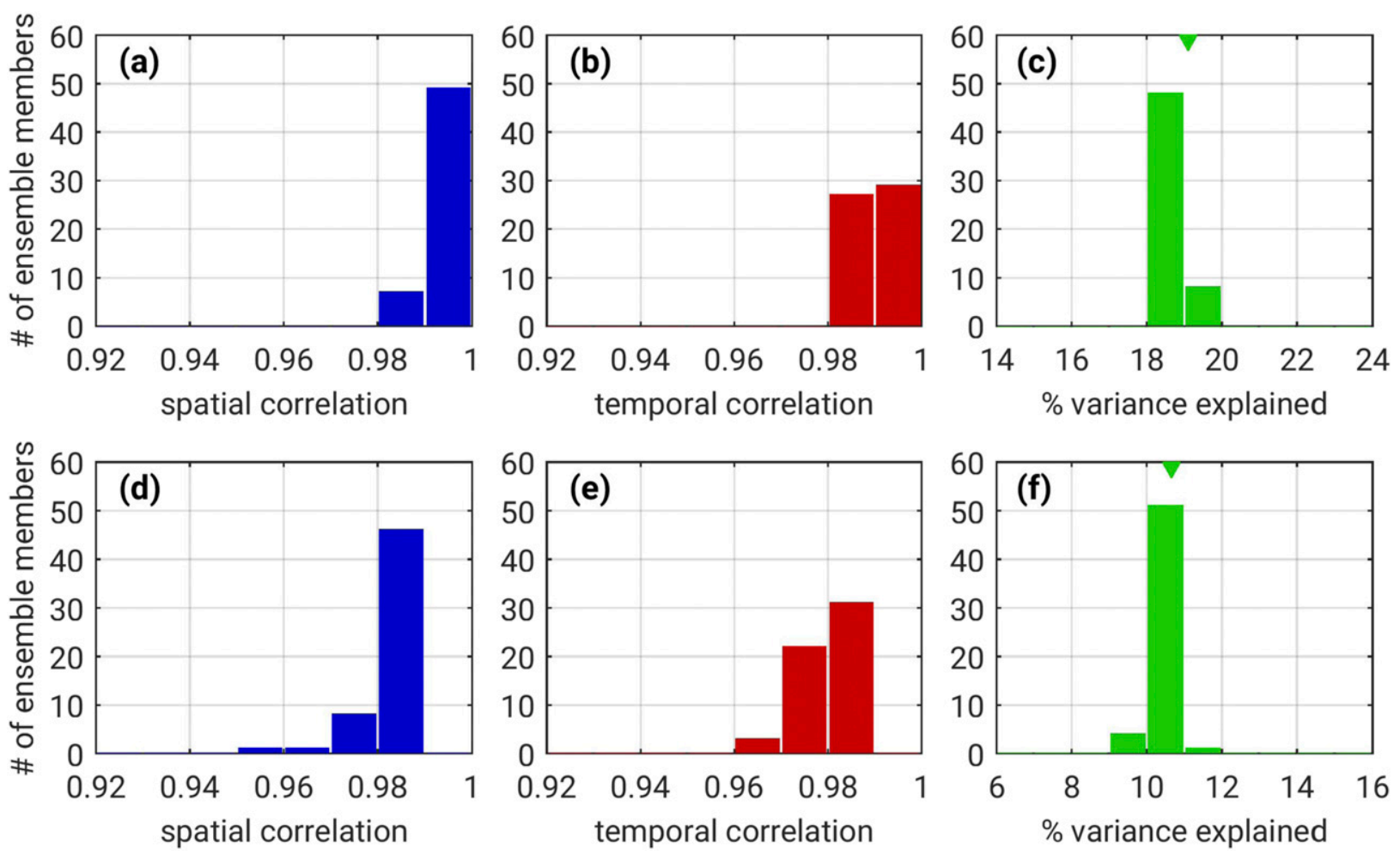

FIG. A2. Histograms for the comparison between the leading EOFs from the ensemble mean fields and the 56 individual ensemble members, for the (top) first and (bottom) second EOF modes. The histograms are for (a),(d) the spatial correlations of the EOF patterns, (b),(e) the temporal correlations between the PC time series, and (c),(f) the portion of the variance explained with the inverse triangle indicating the value from the ensemble mean field EOFs.

This optimal SST anomaly pattern exhibits maximum SST anomalies in the western subpolar gyre, especially from the Tail of the Grand Banks to the Flemish Cap. It is noteworthy that this SST anomaly pattern is different from the canonical AMV pattern (e.g., Ting et al. 2009; Guan and Nigam 2009), which is obtained as a simultaneous regression on the AMV index time series. Note that most of the modeling studies specify the canonical AMV pattern to examine the atmospheric responses to the AMV (Peings and Magnusdottir 2014, 2016; Davini et al. 2015; Ruprich-Robert et al. 2017). However, our results indicate that there is perhaps an SST anomaly pattern that optimally perturbs the atmosphere or the entire evolution of SST anomaly may be important. It would be worthwhile to ask how the previous modeling results would compare if they used these optimal SST anomalies or the full temporal evolution of AMV SST anomalies.

Intriguingly, the evolution of SST anomalies is very different in the warm and cold phase of the AMV, and hence the response of the blocking is also sensitive to the sign of AMV. Alexander et al. (2014) also pointed out that the SST anomaly pattern for every single warm or cold epoch between 1871 and 2008 is distinct. This could be attributed to poor data availability, especially in the early years. However, even their most recent cold epoch (1968-94) and warm epoch (1995-2008) exhibited very distinct patterns, which are very similar to our lag $=0$ year composites for the cold and warm AMV phases, respectively. As the dominant multidecadal variability allows a very limited degree of freedom from the observational records, the robustness of the asymmetry in the AMV phases could be further examined using long climate model simulations. More importantly, how the ocean circulation drives the AMV (e.g., Knight et al. 2005; Häkkinen et al. 2011b) needs to be further investigated to better understand the different SST evolutions in the warm and cold phase of AMV.

For the warm phase of AMV, the warm SST anomalies in the western subpolar gyre are damped by the surface heat flux, and thus pose anomalous heating in the lower troposphere and reduce the overall meridional gradient of the atmospheric temperature. Consequently, the baroclinicity and the meridional synoptic transient eddy heat flux (i.e., the storm track activity) weaken. The weakened transient eddy heat flux results in cyclonic wave breaking, and thus the eddy-driven jet shifts equatorward and becomes more zonal (Novak et al. 

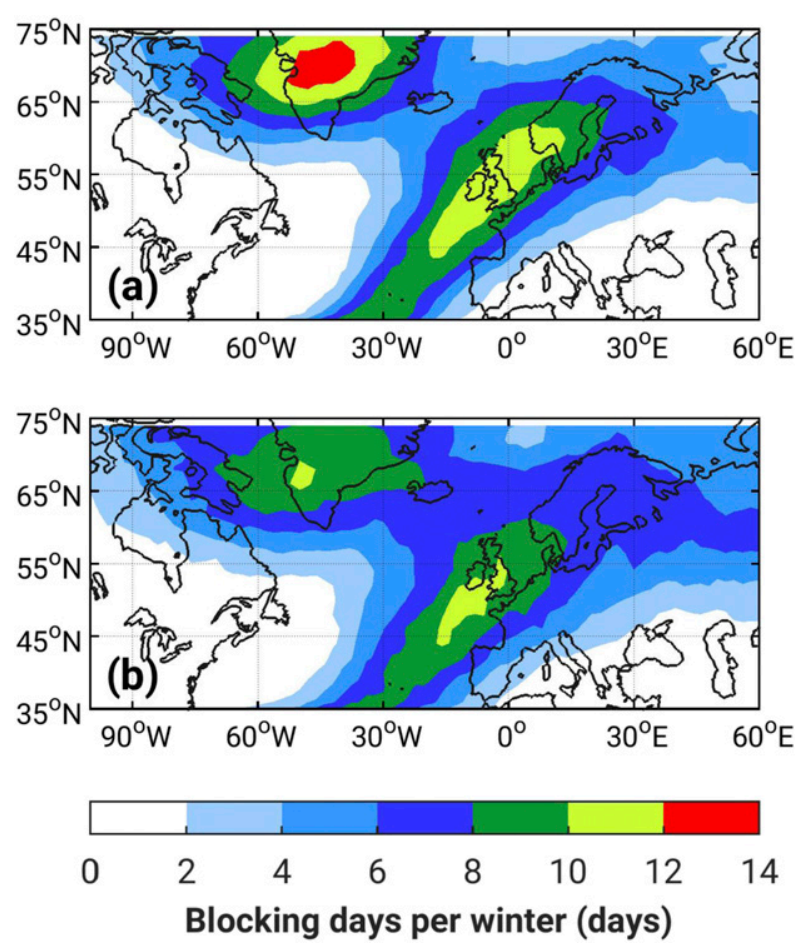

FIG. B1. (a) Climatological mean and (b) interannual standard deviation of the winter (December-March) number of blocking days for 1901-2010 based on the daily Z500 of the ERA-20C.

2015; O'Reilly et al. 2016b, 2017a). The southerly jet is further accompanied by enhanced Rossby wave breaking on the northern flank of the jet over Greenland and reduced wave breaking to the south over the Azores. As the blocking substantially influences the seasonal mean atmospheric circulation, the negative phase of NAO dominates at the same time. Our result is consistent with previous studies focused only on the relationship between the AMV and NAO (Peings and Magnusdottir 2014; Gastineau and Frankignoul 2015). It is noteworthy that our result suggests a primary role for the extratropical part of the AMV SST anomalies, which is consistent with Peings and Magnusdottir $(2014,2016)$ and Gastineau et al. (2016). Also note that this relationship is primarily on the multidecadal time scale. The NAO is also correlated with the leading mode of the winter blocking frequency, which is predominantly on an interannual to decadal time scale and not significantly correlated with AMV.

Our analysis is limited by the length of the dataset and dominant multidecadal time scale of AMV. In particular, our composite analysis is dictated by essentially one cycle of AMV, the warm phase from the 1930s to 1960s and the following cold phase from the 1970s to 1990s (Fig. 4b). We assessed the robustness of the result from the ensemble mean field of the $20 \mathrm{CR}$ in two different ways. First, we analyzed all 56 ensemble members to find a very small ensemble spread in terms of blocking statistics (appendix A). This result suggests that the reanalysis is primarily constrained by the assimilated observational data, and impact from the model's internal variability is limited. In addition, we examined the ERA-20C to find that the blocking statistics and evolution of blocking anomalies with respect to AMV is consistent with 20CR (appendix B). An alternative approach to assess the robustness of our finding could be a general circulation model experiment with prescribed AMV SST anomalies, which we plan to conduct in the near future. Nevertheless, the existing modeling studies with a focus on the NAO (Peings and Magnusdottir 2014, 2016; Omrani et al. 2014, 2016; Ruprich-Robert et al. 2017) or blocking (Davini et al. 2015) support our finding, as already discussed. At the same time, these modeling studies suggest different mechanisms, probably due to model dependency. For example, some modeling studies found the dominant role for the tropical AMV forcing (Davini et al. 2015), while others found the midlatitude AMV forcing to be important (Peings and Magnusdottir 2014, 2016; Gastineau et al. 2016). Also, some modeling studies found a critical role for the stratospheric pathway (Omrani et al. 2014, 2016), while others showed similar results with and without a well-resolved stratosphere (Peings and Magnusdottir 2016). Therefore, our observational analysis can contribute to resolving the discrepancies among the models.

The blocking variability driven by the AMV projects well on the second EOF pattern of the winter blocking frequency, as we have shown. However, it is noteworthy that AMV-driven blocking anomalies are concentrated over Greenland and the Azores without much action over the British Isles to Scandinavia. The enhanced blocking over the British Isles and Scandinavia is found when the jet is near its central latitude (Woollings et al. 2010). Hence, the AMV-driven blocking anomalies involve primarily the changes in the jet position between its northern and southern positions, without a significant anomaly around the central jet position (Figs. 13c,f,i). While we have highlighted the importance of the overall changes in the daily eddy-driven jet latitude (i.e., a seasonal mean sense), Woollings et al. (2018) reported that the same second EOF mode is highly correlated with a different aspect of the jet variability, namely changes in intraseasonal variability of the daily jet latitude (i.e., the seasonal variance). When the jet speed is relatively weaker, the jet wobbles more meridionally and blocking becomes more frequent over the broad subpolar latitudes from Greenland to Scandinavia with the most frequent blocking over the North Sea (i.e., the opposite phase of the pattern shown in Fig. 2b). If the jet 

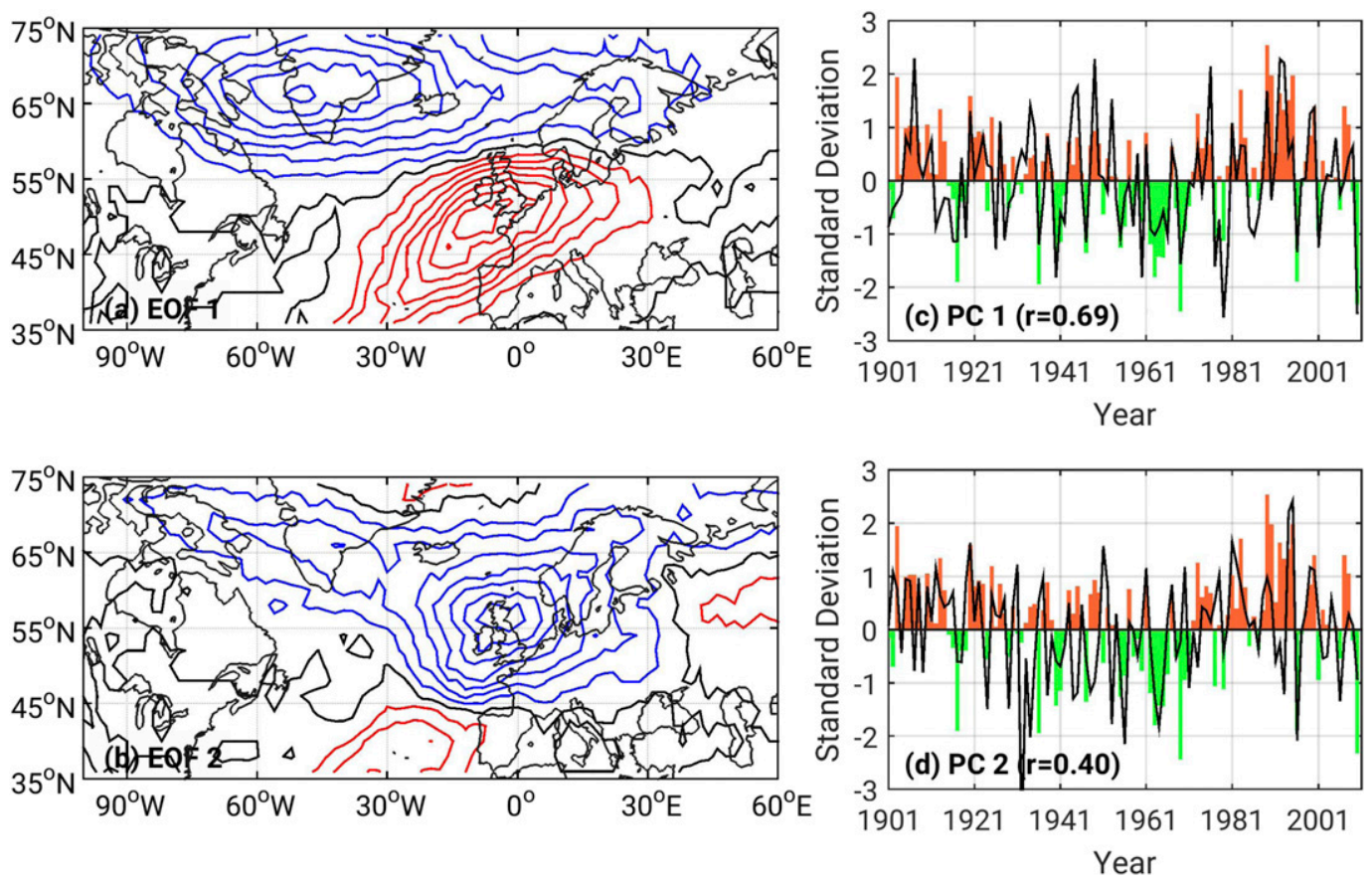

FIG. B2. (a),(b) Leading EOF patterns of the winter (December-March) number of blocking days for 1901-2010 based on ERA-20C. These two EOFs explain $20.9 \%$ and $11.5 \%$ of the total variance, respectively. Note that the amplitudes of the patterns correspond to one standard deviation of the corresponding PC time series. Red (blue) contours indicate positive (negative) anomalies. Contour intervals are 1 day. (c),(d) The corresponding PC time series (black curves) and the NAO index time series (orange and green bars). The correlation between each PC time series and NAO index is shown in parentheses.

wobbles preferentially between the southern and central positions, blocking would be enhanced over the broader subpolar latitude. It needs to be investigated why the intraseasonal variance of the jet latitude exhibits multidecadal variability and whether it is also driven by the AMV.

In our study, we focused on the multidecadal component of the AMV and its impact on the atmosphere. In addition to the multidecadal variability, the AMV also possesses significant decadal variability (Nigam et al. 2018). In particular, Nigam et al. (2018) showed that the decadal component of the AMV is closely related to the Gulf Stream variability: that is, the northward shift of the Gulf Stream path coincides with the cold AMV phase with cold SST anomalies in the subpolar gyre. However, the SST anomalies associated with the Gulf Stream path shift have stronger and oppositely signed anomalies near the Gulf Stream compared to those in the subpolar gyre (Frankignoul et al. 2001; Kwon and Joyce 2013), unlike the AMV SST anomalies. Furthermore, Nigam et al. (2018) hypothesized that the NAO responds to the decadal component of AMV. Using various reanalyses for 1979-2012, Joyce et al. (2019) showed that the northward shift of the Gulf Stream path precedes the reduced blocking occurrence over Greenland and more northeasterly storm track by $1-3$ months. If this relationship is mediated through the cold SST anomalies in the subpolar gyre as Nigam et al. (2018) hypothesized, the relationship may be consistent with the multidecadal relationship found in our study. Joyce et al. (2019) noted that their relationship does not hold prior to the mid1970s, which implies a potential nonstationarity. However, it is not yet clear what the main source of the nonstationarity is (i.e., whether ocean or atmosphere or both).

Our study was originally motivated by Häkkinen et al. (2011a), who interpreted the coherent multidecadal variability in blocking and the AMV as the blocking-related atmospheric circulation driving the AMV. On the other hand, we showed that the multidecadal variability in the blocking can be driven by the AMV. Combining those two aspects together, a two-way coupled mode of variability between the AMV and atmospheric blocking could exist. A more detailed mechanism for such a coupled mode of variability, including the source of the multidecadal time scale, needs to be investigated.

Acknowledgments. We gratefully acknowledge support from the NSF Climate and Large-scale Dynamics Program (AGS-1355339) to Y-OK, HS, CCU, and TMJ, the NASA Physical Oceanography Program (NNX13AM59G) to 
(a) AMV lags by $1 \mathrm{yr}$

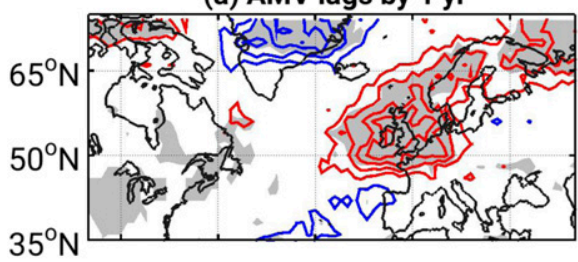

(d) AMV leads by 2 yr

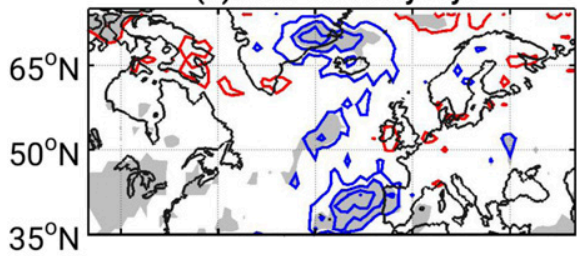

(g) AMV leads by 5 yr

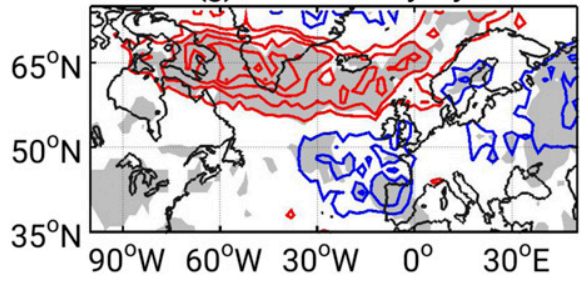

(b) AMV leads by 0 yr

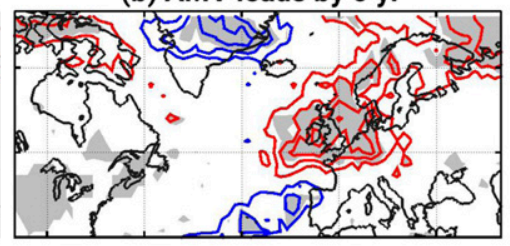

(e) AMV leads by $3 \mathrm{yr}$

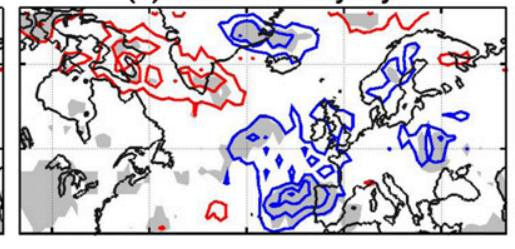

(h) AMV leads by 6 yr

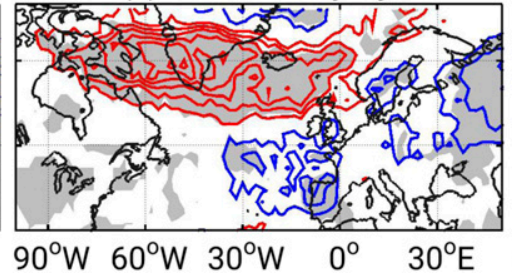

(c) AMV leads by $1 \mathrm{yr}$

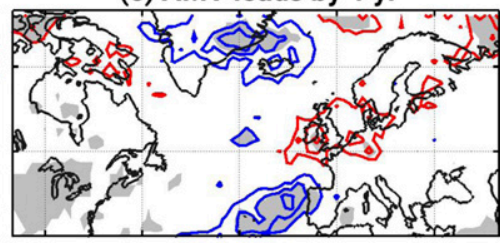

(f) AMV leads by 4 yr

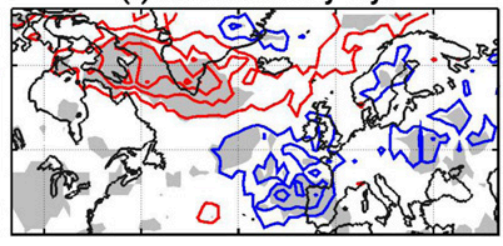

(i) AMV leads by $7 \mathrm{yr}$

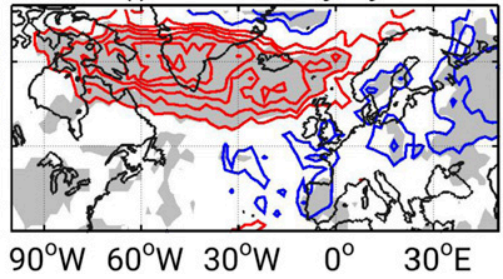

FIG. B3. (a)-(i) Lag composite of the winter (December-March) number of blocking days from ERA-20C with respect to the upper 20th percentile years of the 10-yr low-pass filtered AMV index. Note that a binomial smoothing is applied to the number of blocking days prior to compositing as explained in section 2c. Contour interval is 1 day. Red (blue) contours are for the positive (negative) anomalies. Zero contours are omitted. Gray shading indicates anomalies statistically significant at the $5 \%$ level. Influence from the tropical Indo-Pacific SST is minimized from both the SST and AMV index before compositing, except for (a) and (b) as explained in section 2c.

Y-OK, HS, and TMJ, NOAA CPO Climate Variability and Predictability Program (NA13OAR4310139) and DOE CESD Regional and Global Model Analysis Program (DE-SC0019492) to Y-OK, and NSF Physical Oceanography Program (OCE-1419235) to HS. We are very grateful to the three anonymous reviewers and editor Dr. Mingfang Ting, for their thorough and insightful suggestions. The NOAA 20CR dataset was downloaded from the NOAA Earth System Research Laboratory Physical Science Division webpage (https://www.esrl.noaa. gov/psd/data/20thC_Rean/). Support for the 20CR Project version $2 c$ dataset is provided by the U.S. Department of Energy, Office of Science Biological and Environmental Research (BER), and by the National Oceanic and Atmospheric Administration Climate Program Office. The HadISST dataset was downloaded from the U.K. Met Office Hadley Centre webpage (https://www.metoffice.gov. uk/hadobs/hadisst/). The ERA-20C dataset was downloaded from the ECMWF webpage (https://apps.ecmwf. int/datasets/data/era20c-daily/). The ERSST5 dataset was provided by the NOAA Earth System Research Laboratory Physical Science Division (https:/www.esrl.noaa.gov/ psd/data/gridded/data.noaa.ersst.v5.html).

\section{APPENDIX A}

\section{NOAA 20CR Ensemble Spread}

The statistics of winter blocking days are calculated from the 56 individual ensemble members of the 20CR and compared to the corresponding statistics using the ensemble mean fields of the 20CR shown in the main text. First, the climatological mean and interannual standard deviation of the number of blocking days during winter are calculated. The ensemble mean of 56 climatological means and interannual standard deviations (Fig. A1) are almost identical to the corresponding plots using the ensemble mean fields (Fig. 1). Furthermore, the ensemble spread, which is shown as the standard deviation among 56 members (red contours in Fig. A1), is generally small with an amplitude of 0.2 days in most locations.

Next, the leading EOFs are calculated from the individual members and compared against those using the ensemble mean fields. Three different measures are compared for each EOF mode (Fig. A2). First, the spatial correlations between the EOF spatial pattern from the ensemble mean field and that from each of 56 
(a) AMV lags by $1 \mathrm{yr}$

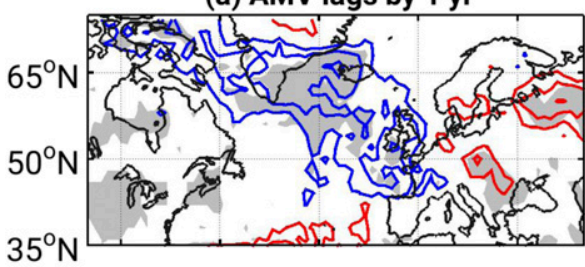

(d) AMV leads by $2 \mathrm{yr}$

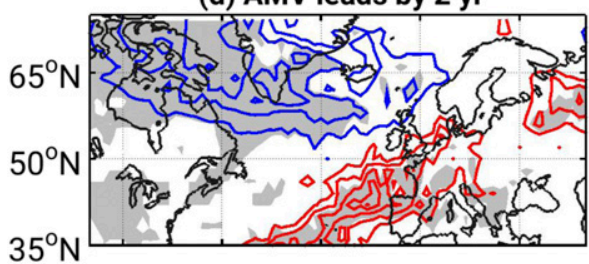

(g) AMV leads by 5 yr

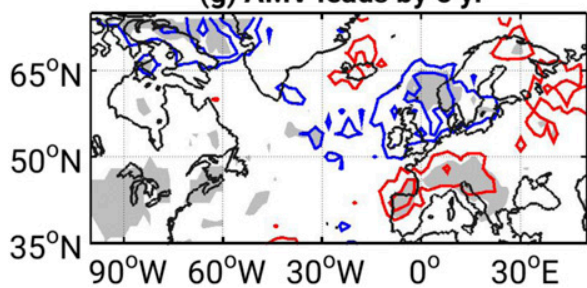

(b) AMV leads by 0 yr

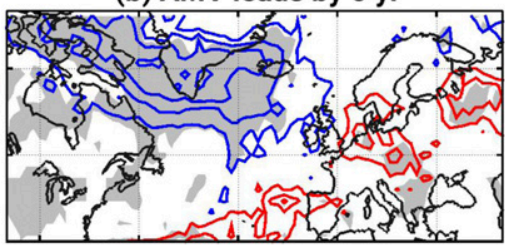

(e) AMV leads by 3 yr

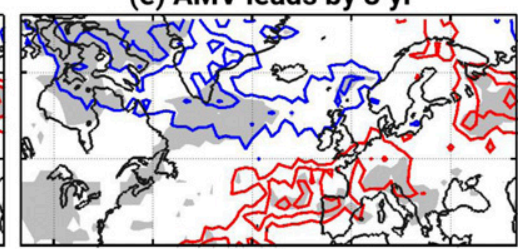

(h) AMV leads by 6 yr

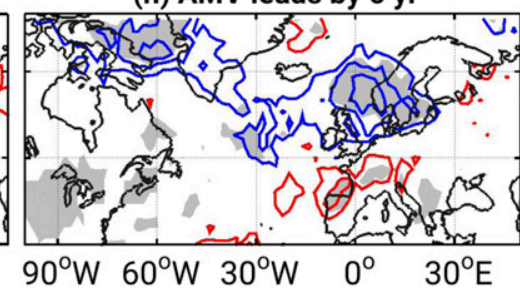

(c) AMV leads by $1 \mathrm{yr}$

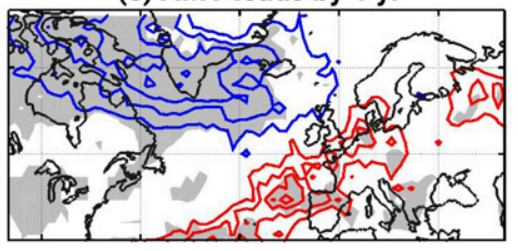

(f) AMV leads by $4 \mathrm{yr}$

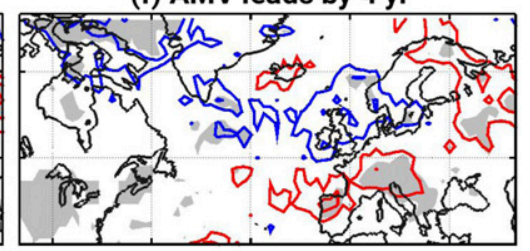

FIG. B4. As in Fig. B3, but for the lower 20th percentile years of the 10-yr low-pass filtered AMV index.

members are calculated (Figs. A2a,d). The result shows that all 56 members have spatial correlations greater than 0.98 (0.95) for EOF1 (EOF2). We also calculated the correlations between the PC time series, similarly (Figs. A2b,e). Again, all 56 members have temporal correlations greater than 0.98 (0.96) for PC1 (PC2). Finally, the portion of total variance explained by EOF1 (EOF2) of 56 members is within $1 \%(2 \%)$ of that using the ensemble mean fields (Figs. A2c,f).

Our results indicate that the data used for the 20CR, which are the surface pressure, SST, and sea ice concentration, constrain the AGCM to such a degree as to produce consistent solutions across the 56 ensemble members at least for the two leading EOFs. We have also repeated the same test for the first and second halves of the record separately and found that the conclusion still holds, although the first half showed slightly larger ensemble spread (not shown). The ensemble spreads become larger for the higher EOFs as the modes become more dependent on regional features.

\section{APPENDIX B}

\section{Comparison between the 20CR and ERA20C}

The climatological mean and interannual standard deviation of the number of winter blocking days based on
ERA-20C (Fig. B1) exhibit spatial patterns very similar to those from 20CR (Fig. 1). The largest discrepancy is found over Greenland, where ERA-20C shows more than twice as many blocking days in the mean and $\sim 50 \%$ stronger variability. The leading EOFs for the number of winter blocking days from the two datasets also reveal very similar spatial patterns as well as temporal evolutions (Fig. B2 vs Fig. 2). The EOF1 spatial pattern shows a greater loading over Greenland in the ERA-20C compared to the $20 \mathrm{CR}$. The spatial correlation between the EOF1 (EOF2) from the two datasets is 0.92 (0.89), while the temporal correlation for the corresponding PCs is 0.89 (0.85). Finally, the lag composite of the number of winter blocking days anomalies with respect to the 10-yr lowpass filtered AMV index is examined from the ERA-20C (Figs. B3 and B4). The evolution of the blocking anomalies following the AMV is also consistent with that from the 20CR (Figs. 10 and 11) for both the warm and cold phases of AMV.

\section{APPENDIX C}

\section{Comparison between HadISST and ERSST5}

The SST composites for the warm and cold AMV years are calculated using ERSST5 (Figs. C1 and C2) to 
(a) AMV lags by $1 \mathrm{yr}$

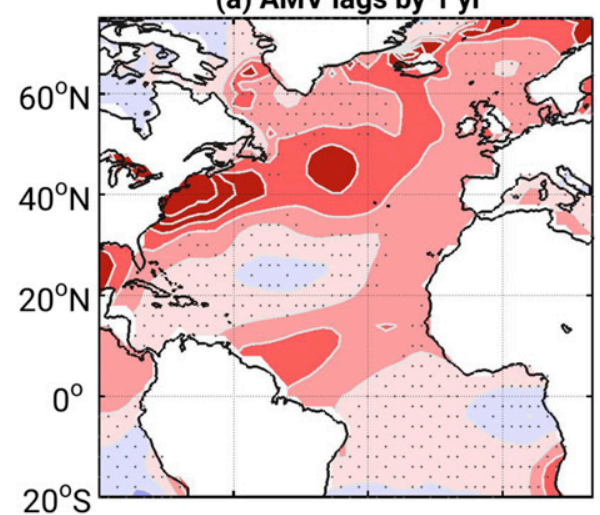

(d) AMV leads by $2 \mathrm{yr}$

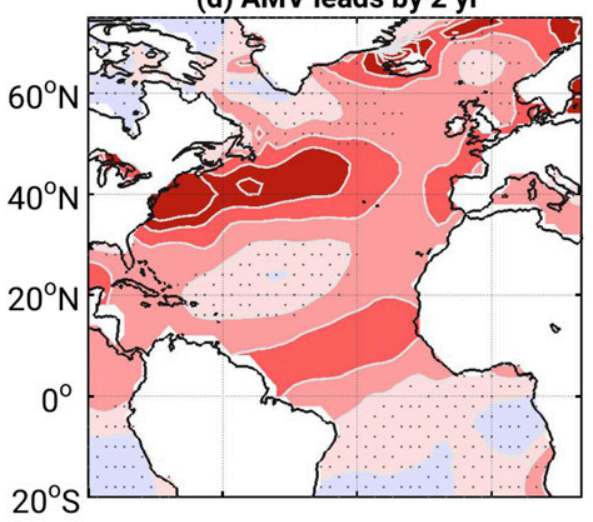

(g) AMV leads by $5 \mathrm{yr}$

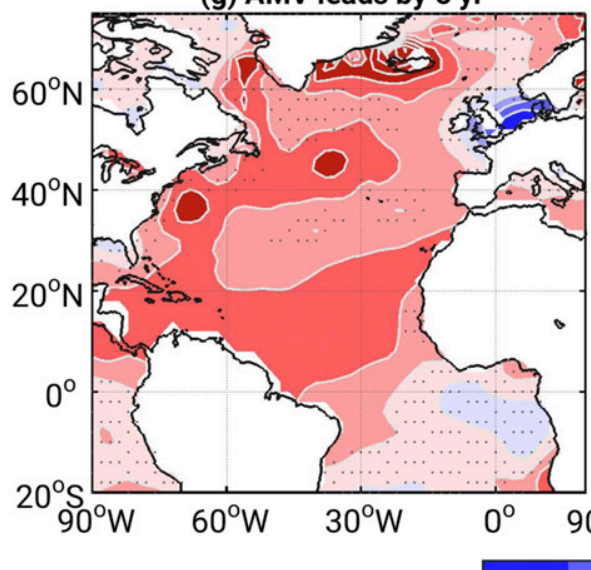

(b) AMV leads by 0 yr

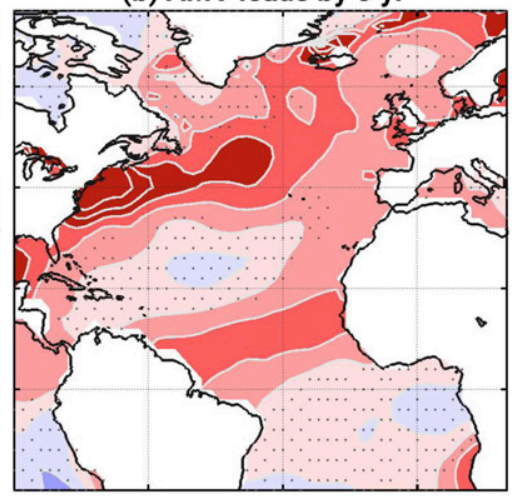

(e) AMV leads by 3 yr

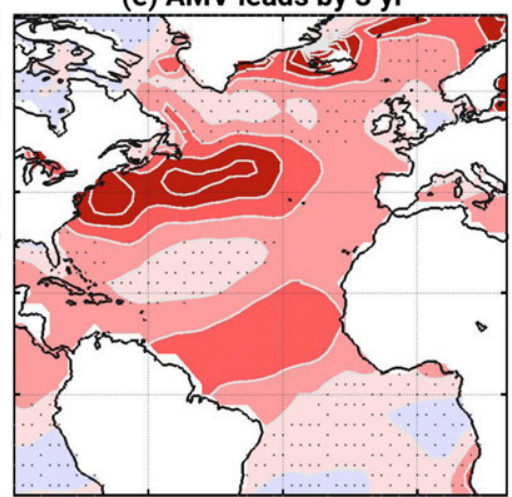

(h) AMV leads by $6 \mathrm{yr}$

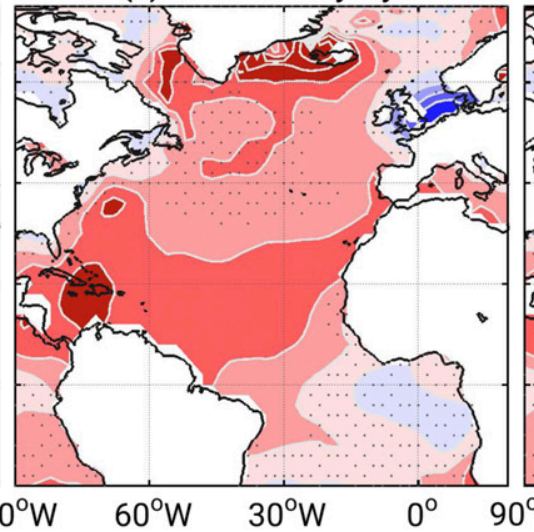

$90^{\circ} \mathrm{W}$ (c) AMV leads by $1 \mathrm{yr}$

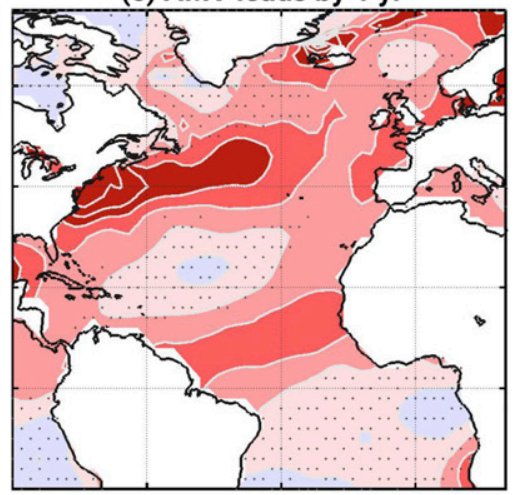

(f) AMV leads by $4 \mathrm{yr}$

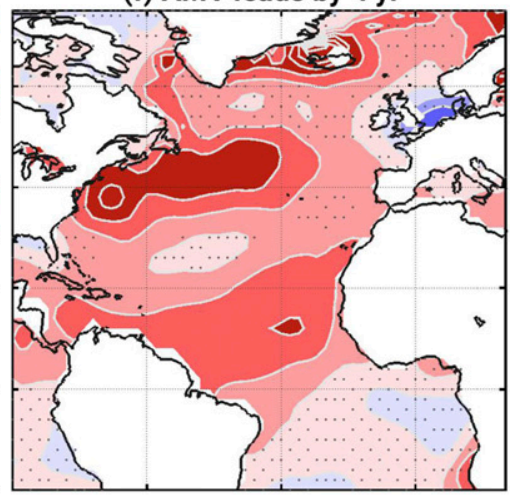

(i) AMV leads by $7 \mathrm{yr}$

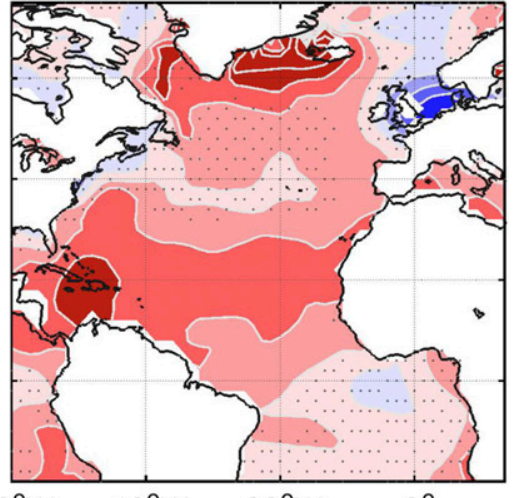

\begin{tabular}{cccc}
-0.4 & $-0.2 \quad 0$ & 0.4 \\
\multicolumn{4}{c}{ SST anomalies $\left({ }^{\circ} \mathrm{C}\right)$}
\end{tabular}

FIG. C1. As in Fig. 8, but using ERSST5.

assess the robustness of the findings based on HadISST (Figs. 8 and 9). Partly due to the differences in their horizontal resolutions $\left(2^{\circ}\right.$ for ERSST5 vs $1^{\circ}$ for HadISST), the ERSST5 composite maps exhibit a much smoother spatial distribution of the anomalies. Nevertheless, the two SST datasets provide overall consistent results. In particular, the cold AMV composites (Fig. 9 vs Fig. C2) show very similar evolutions of the cold SST anomalies centered in the subpolar gyre. For the warm AMV composites (Fig. 8 vs Fig. C1), the coarser resolution in the 
(a) AMV lags by $1 \mathrm{yr}$

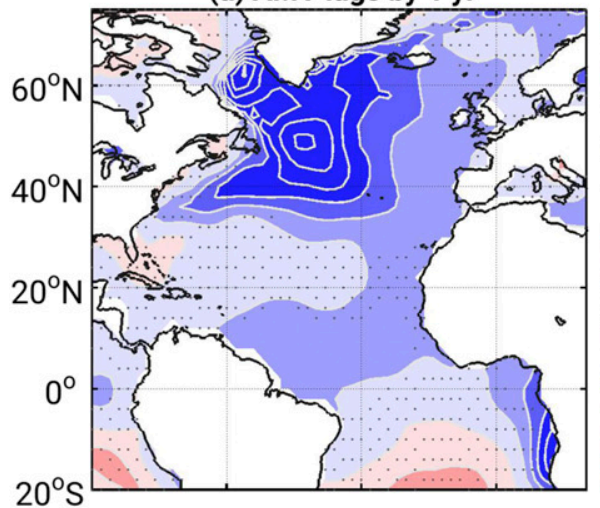

(d) AMV leads by $2 \mathrm{yr}$

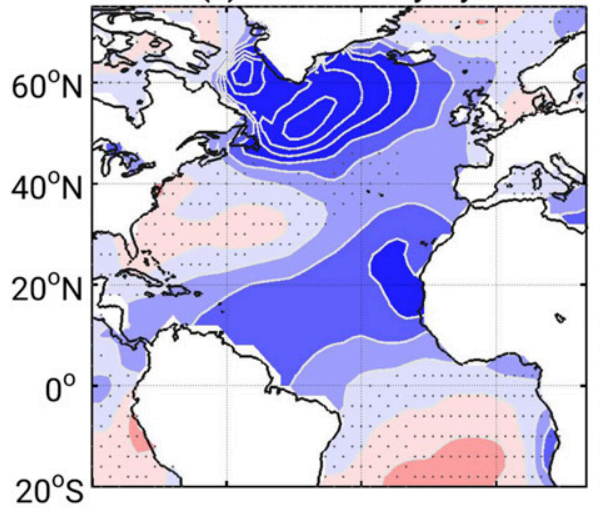

(g) AMV leads by $5 \mathrm{yr}$

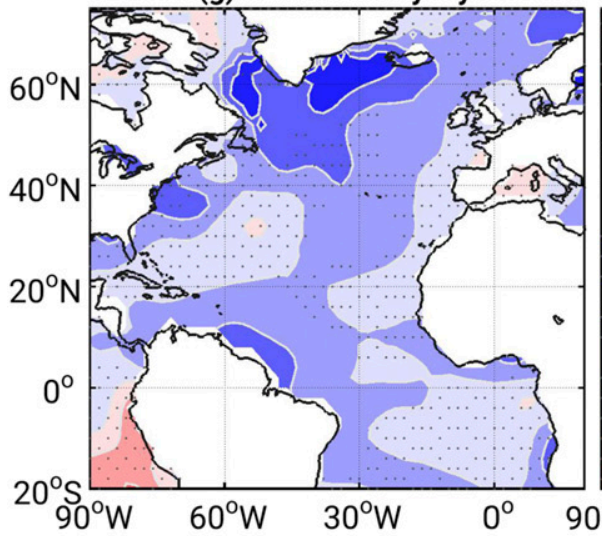

(h) AMV leads by 6 yr
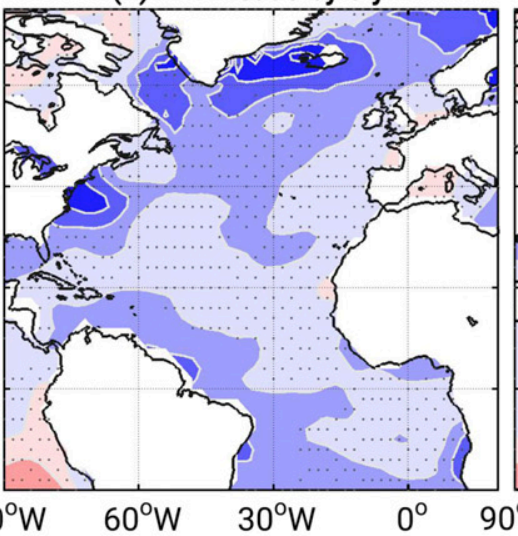

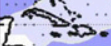

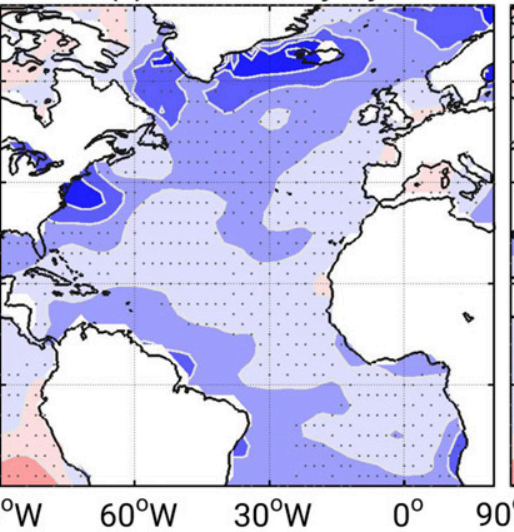

$0^{\circ} \mathrm{W}$

(b) AMV leads by 0 yr

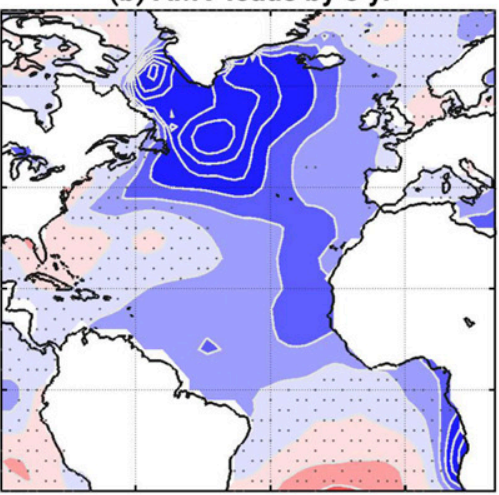

(e) AMV leads by $3 \mathrm{yr}$

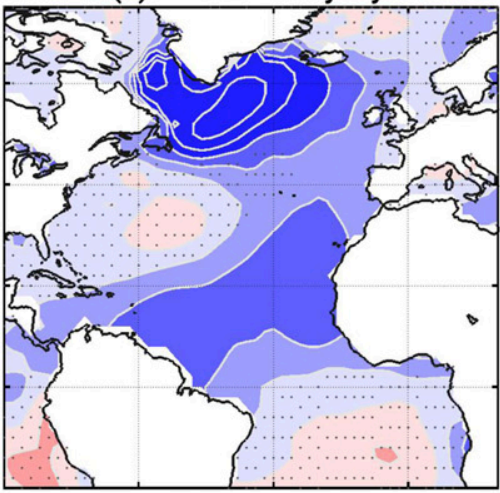

0.2

0

SST anomalies $\left({ }^{\circ} \mathrm{C}\right)$ (c) AMV leads by $1 \mathrm{yr}$

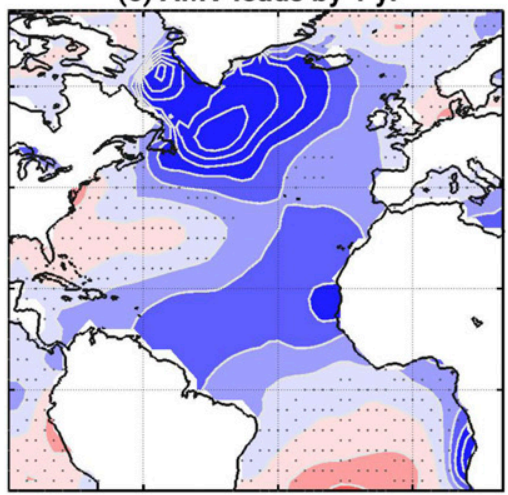

(f) AMV leads by $4 \mathrm{yr}$

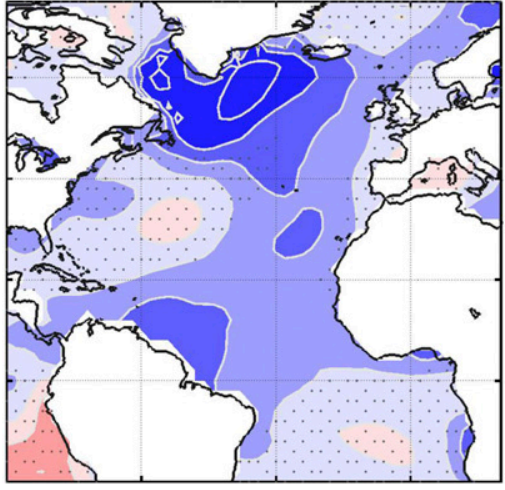

(i) AMV leads by $7 \mathrm{yr}$

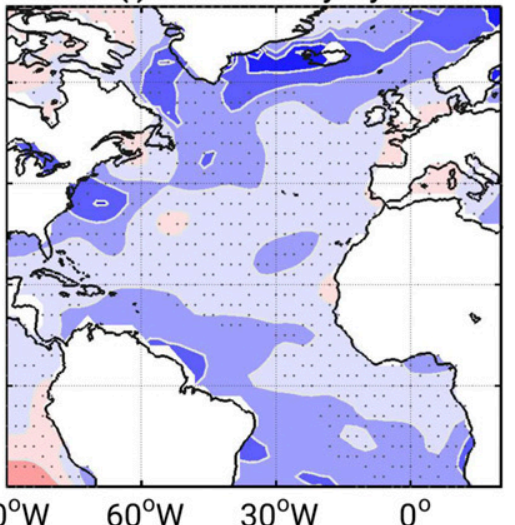

0.4

FIG. C2. As in Fig. 9, but using ERSST5.

ERSST5 resulted in broader and less concentrated maximum warm SST anomalies near the Gulf Stream and North Atlantic Current compared to the SST anomalies in the HadISST that are more concentrated near the Tail of the Grand Banks.

\section{REFERENCES}

Alexander, M. A., K. Halimeda Kilbourne, and J. A. Nye, 2014: Climate variability during warm and cold phases of the Atlantic Multidecadal Oscillation (AMO) 1871-2008. J. Mar. Syst., 133, 14-26, https://doi.org/10.1016/j.jmarsys.2013.07.017. 
Barnes, E. A., and D. L. Hartmann, 2010: Influence of eddy-driven jet latitude on North Atlantic jet persistence and blocking frequency in CMIP3 integrations. Geophys. Res. Lett., 37, L23802, https://doi.org/10.1029/2010GL045700.

_- J. Slingo, and T. Woollings, 2012: A methodology for the comparison of blocking climatologies across indices, models and climate scenarios. Climate Dyn., 38, 2467-2481, https:// doi.org/10.1007/s00382-011-1243-6.

Barnston, A. G., and R. E. Livezey, 1987: Classification, seasonality and persistence of low-frequency atmospheric circulation patterns. Mon. Wea. Rev., 115, 1083-1126, https://doi.org/10.1175/ 1520-0493(1987)115<1083:CSAPOL > 2.0.CO;2.

Benedict, J. J., S. Lee, and S. B. Feldstein, 2004: Synoptic view of the North Atlantic Oscillation. J. Atmos. Sci., 61, 121-144, https:// doi.org/10.1175/1520-0469(2004)061<0121:SVOTNA > 2.0.CO;2.

Compo, G. P., J. S. Whitaker, and P. D. Sardeshmukh, 2006: Feasibility of a 100-year reanalysis using only surface pressure data. Bull. Amer. Meteor. Soc., 87, 175-190, https://doi.org/ 10.1175/BAMS-87-2-175.

— Project. Quart. J. Roy. Meteor. Soc., 137, 1-28, https://doi.org/ 10.1002/qj. 776.

Coumou, D., and S. Rahmstorf, 2012: A decade of weather extremes. Nat. Climate Change, 2, 491-496, https://doi.org/10.1038/ nclimate1452.

Davini, P., and C. Cagnazzo, 2014: On the misinterpretation of the North Atlantic Oscillation in CMIP5 models. Climate Dyn., 43, 1497-1511, https://doi.org/10.1007/s00382-0131970-y.

-, , R. Neale, and J. Tribbia, 2012: Coupling between Greenland blocking and the North Atlantic Oscillation pattern. Geophys. Res. Lett., 39, L14701, https://doi.org/10.1029/ 2012 GL052315.

— J. V. Hardenberg, and S. Corti, 2015: Tropical origin for the impacts of the Atlantic multidecadal variability on the EuroAtlantic climate. Environ. Res. Lett., 10, 094010, https://doi. org/10.1088/1748-9326/10/9/094010.

Deser, C., A. S. Phillips, V. Bourdette, and H. Teng, 2012: Uncertainty in climate change projections: The role of internal variability. Climate Dyn., 38, 527-546, https://doi.org/10.1007/ s00382-010-0977-x.

Duchon, C. E., 1979: Lanczos filtering in one and two dimensions. J. Appl. Meteor., 18, 1016-1022, https://doi.org/10.1175/15200450(1979)018<1016:LFIOAT >2.0.CO;2.

Ebisuzaki, W., 1997: A method to estimate the statistical significance of a correlation when the data are serially correlated. J. Climate, 10, 2147-2153, https://doi.org/10.1175/1520-0442(1997)010<2147: AMTETS $>2.0 . \mathrm{CO} ; 2$.

Enfield, D. B., A. M. Mestas-Nuñez, and P. J. Trimble, 2001: The Atlantic multidecadal oscillation and its relation to rainfall and river flows in the continental U.S. Geophys. Res. Lett., 28, 2077-2080, https://doi.org/10.1029/2000GL012745.

Folland, C. K., T. N. Palmer, and D. E. Parker, 1986: Sahel rainfall and worldwide sea temperature 1901-85. Nature, 320, 602607, https://doi.org/10.1038/320602a0.

Frankignoul, C., and E. Kestenare, 2002: The surface heat flux feedback. Part I: Estimates from observations in the Atlantic and the North Pacific. Climate Dyn., 19, 633-647, https:// doi.org/10.1007/s00382-002-0252-x.

, G. de Coetlogon, T. M. Joyce, and S. F. Dong, 2001: Gulf Stream variability and ocean-atmosphere interactions. J. Phys. Oceanogr., 31, 3516-3529, https://doi.org/10.1175/1520-0485(2002) $031<3516$ :GSVAOA $>2.0 . \mathrm{CO} ; 2$.
—, N. Sennéchael, Y.-O. Kwon, and M. A. Alexander, 2011: Atmosphere-ocean variability associated with Kuroshio and Oyashio Extension fluctuations. J. Climate, 24, 762-777, https:// doi.org/10.1175/2010JCLI3731.1.

García-García, D., and C. C. Ummenhofer, 2015: Multidecadal variability of the continental precipitation annual amplitude driven by AMO and ENSO. Geophys. Res. Lett., 42, 526-535, https://doi.org/10.1002/2014GL062451.

Gastineau, G., and C. Frankignoul, 2012: Cold-season atmospheric response to the natural variability of the Atlantic meridional overturning circulation. Climate Dyn., 39, 37-57, https:// doi.org/10.1007/s00382-011-1109-y.

$\longrightarrow$, and — 2015: Influence of the North Atlantic SST variability on the atmospheric circulation during the twentieth century. J. Climate, 28, 1396-1416, https://doi.org/10.1175/JCLID-14-00424.1.

— B. B'Hévéder, F. Codron, and C. Frankignoul, 2016: Mechanisms determining the winter atmospheric response to the Atlantic overturning circulation. J. Climate, 29, 3767-3785, https://doi.org/10.1175/JCLI-D-15-0326.1.

Goldenberg, S. B., C. W. Landsea, A. M. Mestas-Nuñez, and W. M. Gray, 2001: Hurricane activity: Causes and implications. Science, 293, 474-479, https://doi.org/10.1126/science.1060040.

Guan, B., and S. Nigam, 2009: Analysis of Atlantic SST variability factoring interbasin links and the secular trend: Clarified structure of the Atlantic multidecadal oscillation. J. Climate, 22, 4228-4240, https://doi.org/10.1175/2009JCLI2921.1.

Gulev, S. K., M. Latif, N. Keenlyside, W. Park, and K. P. Koltermann, 2013: North Atlantic Ocean control on surface heat flux on multidecadal timescales. Nature, 499, 464-467, https://doi.org/10.1038/nature12268.

Häkkinen, S., P. B. Rhines, and D. L. Worthen, 2011a: Atmospheric blocking and Atlantic multidecadal ocean variability. Science, 334, 655-659, https://doi.org/10.1126/science.1205683.

,-- , and,$- 2011 \mathrm{~b}$ : Warm and saline events embedded in the meridional circulation of the northern North Atlantic. J. Geophys. Res., 116, C03006, https://doi.org/10.1029/ 2010JC006275.

Huang, B., and Coauthors, 2017: Extended Reconstructed Sea Surface Temperature version 5 (ERSSTv5), Upgrades, validations, and intercomparisons. J. Climate, 30, 8179-8205, https://doi.org/ 10.1175/JCLI-D-16-0836.1.

Hurrell, J. W., 1995: Decadal trends in the North Atlantic Oscillation: Regional temperatures and precipitation. Science, $\mathbf{2 6 9}$, 676-679, https://doi.org/10.1126/science.269.5224.676.

Jones, P. D., M. New, D. E. Parker, S. Martin, and I. G. Rigor, 1999: Surface air temperature and its variations over the last 150 years. Rev. Geophys., 37, 173-199, https://doi.org/10.1029/1999RG900002.

Joyce, T. J., Y.-O. Kwon, H. Seo, and C. C. Ummenhofer, 2019: Meridional Gulf Stream shifts can influence wintertime variability in the North Atlantic storm track and Greenland blocking. Geophys. Res. Lett., 46, 1702-1708, https://doi.org/10.1029/2018GL081087.

Kerr, R. A., 2000: A North Atlantic climate pacemaker for the centuries. Science, 288, 1984-1986, https://doi.org/10.1126/science. 288.5473.1984.

Knight, J. R., R. J. Allan, C. K. Folland, M. Vellinga, and M. E. Mann, 2005: A signature of persistent natural thermohaline circulation cycles in observed climate. Geophys. Res. Lett., 32, L20708, https://doi.org/10.1029/2005GL024233.

Kushnir, Y., R. Seager, M. Ting, N. Naik, and J. Nakamura, 2010: Mechanisms of tropical Atlantic SST influence on North American precipitation variability. J. Climate, 23, 5610-5628, https://doi.org/10.1175/2010JCLI3172.1. 
Kwon, Y.-O., and T. M. Joyce, 2013: Northern Hemisphere winter atmospheric transient eddy heat fluxes and the Gulf Stream and Kuroshio-Oyashio Extension variability. J. Climate, 26, 9839-9859, https://doi.org/10.1175/JCLI-D-12-00647.1.

_ A. Camacho, C. Martinez, and H. Seo, 2018: North Atlantic winter eddy-driven jet and atmospheric blocking variability in the Community Earth System Model version 1 Large Ensemble simulations. Climate Dyn., 51, 3275-3289, https:// doi.org/10.1007/s00382-018-4078-6.

Lejanäs, H., and H. Økland, 1983: Characteristics of Northern Hemisphere blocking as determined from a long series of observational data. Tellus, 35, 350-362, https://doi.org/10.3402/ tellusa.v35i5.11446.

Luo, D., Y. Yao, and A. Dai, 2015: Decadal relationship between European blocking and the North Atlantic Oscillation during 1978-2011. Part I: Atlantic conditions. J. Atmos. Sci., 72, 11521173, https://doi.org/10.1175/JAS-D-14-0039.1.

Marshall, J., H. Johnson, and J. Goodman, 2001: A study of the interaction of the North Atlantic Oscillation with ocean circulation. J. Climate, 14, 1399-1421, https://doi.org/10.1175/ 1520-0442(2001)014<1399:ASOTIO > 2.0.CO;2.

McIntyre, M. E., and T. N. Palmer, 1983: Breaking planetary waves in the stratosphere. Nature, 305, 593-600, https://doi.org/ 10.1038/305593a0.

Michel, C., and G. Rivière, 2011: The link between Rossby wave breakings and weather regime transitions. J. Atmos. Sci., 68 , 1730-1748, https://doi.org/10.1175/2011JAS3635.1.

Nigam, S., A. Ruiz-Barradas, and L. Chafik, 2018: Gulf Stream excursions and sectional detachments generate the decadal pulses in the Atlantic multidecadal oscillation. J. Climate, $\mathbf{3 1}$, 2853-2870, https://doi.org/10.1175/JCLI-D-17-0010.1.

Novak, L., M. H. P. Ambaum, and R. Tailleux, 2015: The life cycle of the North Atlantic storm track. J. Atmos. Sci., 72, 821-833, https://doi.org/10.1175/JAS-D-14-0082.1.

O'Reilly, C. H., M. Huber, T. Woollings, and L. Zanna, 2016a: The signature of low-frequency oceanic forcing in the Atlantic Multidecadal Oscillation. Geophys. Res. Lett., 43, 2810-2818, https://doi.org/10.1002/2016GL067925.

— S. Minobe, and A. Kuwano-Yoshida, 2016b: The influence of the Gulf Stream on wintertime European blocking. Climate Dyn., 47, 1545-1567, https://doi.org/10.1007/s00382-015-2919-0.

$\longrightarrow,-,-$, and T. Woollings, 2017a: The Gulf Stream influence on wintertime North Atlantic jet variability. Quart. J. Roy. Meteor. Soc., 143, 173-183, https://doi.org/10.1002/qj.2907.

_, T. Woollings, and L. Zanna, 2017b: The dynamical influence of the Atlantic Multidecadal Oscillation on continental climate. J. Climate, 30, 7213-7230, https://doi.org/10.1175/JCLID-16-0345.1.

Omrani, N. E., N. S. Keenlyside, J. Bader, and E. Manzini, 2014: Stratosphere key for wintertime atmospheric response to warm Atlantic decadal conditions. Climate Dyn., 42, 649-663, https:// doi.org/10.1007/s00382-013-1860-3.

— J. Bader, N. S. Keenlyside, and E. Manzini, 2016: Tropospherestratosphere response to large-scale North Atlantic Ocean variability in an atmosphere/ocean coupled model. Climate Dyn., 46, 1397-1415, https://doi.org/10.1007/s00382-0152654-6.

Parker, D. E., C. K. Folland, and M. Jackson, 1995: Marine surface temperature: Observed variations and data requirements. Climatic Change, 31, 559-600, https://doi.org/10.1007/ BF01095162.

Peings, Y., and G. Magnusdottir, 2014: Forcing of the wintertime atmospheric circulation by the multidecadal fluctuations of the
North Atlantic Ocean. Environ. Res. Lett., 9, 034018, https:// doi.org/10.1088/1748-9326/9/3/034018.

- and _- 2016: Wintertime atmospheric response to Atlantic multidecadal variability: Effect of stratospheric representation and ocean-atmosphere coupling. Climate Dyn., 47, 10291047, https://doi.org/10.1007/s00382-015-2887-4.

Pelly, J. L., and B. J. Hoskins, 2003: A new perspective on blocking. J. Atmos. Sci., 60, 743-755, https://doi.org/10.1175/15200469(2003)060<0743:ANPOB > 2.0.CO;2.

Poli, P., H. Hersbach, P. Berrisford, D. Dee, A. Simmons, and P. Laloyaux, 2015: ERA-20C Deterministic. ERA Report Series 20. 53 pp., https://www.ecmwf.int/en/elibrary/11700era-20c-deterministic.

Rayner, N. A., D. E. Parker, E. B. Horton, C. K. Folland, L. V. Alexander, D. P. Rowell, E. C. Kent, and A. Kaplan, 2003: Global analyses of sea surface temperature, sea ice, and night marine air temperature since the late nineteenth century. J. Geophys. Res., 108, 4407, https://doi.org/10.1029/2002JD002670.

Rex, D. F., 1950a: Blocking action in the middle troposphere and its effect upon regional climate. I. An aerological study of blocking action. Tellus, 2, 196-211, https://doi.org/10.3402/ tellusa.v2i3.8546.

1950b: Blocking action in the middle troposphere and its effect upon regional climate. II. The climatology of blocking action. Tellus, 2, 275-301, https://doi.org/10.3402/tellusa.v2i4. 8603.

Rivière, G., 2009: Effect of latitudinal variations in low-level baroclinicity on eddy life cycles and upper-tropospheric wavebreaking processes. J. Atmos. Sci., 66, 1569-1592, https:// doi.org/10.1175/2008JAS2919.1.

Ruprich-Robert, Y., R. Msadek, F. Castruccio, S. Yeager, T. Delworth, and G. Danabasoglu, 2017: Assessing the climate impacts of the observed Atlantic multidecadal variability using the GFDL CM2.1 and NCAR CESM1 global coupled models. J. Climate, 30, 27852810, https://doi.org/10.1175/JCLI-D-16-0127.1.

Scherrer, S. C., M. Croci-Maspoli, C. Schwierz, and C. Appenzeller, 2006: Two-dimensional indices of atmospheric blocking and their statistical relationship with winter climate patterns in the Euro-Atlantic region. Int. J. Climatol., 26, 233-249, https://doi. org/10.1002/joc. 1250 .

Sillmann, J., and M. Croci-Maspoli, 2009: Present and future atmospheric blocking and its impact on European mean and extreme climate. Geophys. Res. Lett., 36, L10702, https://doi. org/10.1029/2009GL038259.

Smith, D. M., R. Eade, Nick J. Dunstone, D. Fereday, J. M. Murphy, H. Pohlmann, and A. A. Scaife, 2010: Skillful multiyear predictions of Atlantic hurricane frequency. Nat. Geosci., 3, 846-849, https://doi.org/10.1038/ngeo1004.

Strong, C., and G. Magnusdottir, 2008: Tropospheric Rossby wave breaking and the NAO/NAM. J. Atmos. Sci., 65, 2861-2876, https://doi.org/10.1175/2008JAS2632.1.

Sutton, R. T., and D. Hodson, 2005: Atlantic Ocean forcing of American and European summer climate. Science, 309, 115118, https://doi.org/10.1126/science.1109496.

and B. Dong, 2012: Atlantic Ocean influence on a shift in European climate in the 1990s. Nat. Geosci., 5, 788-792, https:// doi.org/10.1038/ngeo1595.

Taguchi, B., H. Nakamura, M. Nonaka, N. Komori, A. KuwanoYoshida, K. Takaya, and A. Goto, 2012: Seasonal evolutions of atmospheric response to decadal SST anomalies in the North Pacific subarctic frontal zone: Observations and a coupled model simulation. J. Climate, 25, 111-139, https://doi.org/ 10.1175/JCLI-D-11-00046.1. 
Tibaldi, S., and F. Molteni, 1990: On the operational predictability of blocking. Tellus, 42A, 343-365, https://doi.org/10.3402/ tellusa.v42i3.11882.

Ting, M., Y. Kushnir, R. Seager, and C. Li, 2009: Forced and internal twentieth-century SST trends in the North Atlantic. J. Climate, 22, 1469-1481, https://doi.org/10.1175/2008JCLI2561.1.

,,,--- and -2011 : Robust features of Atlantic multidecadal variability and its climate impacts. Geophys. Res. Lett., 38, L17705, https://doi.org/10.1029/2011GL048712.

von Storch, H., and F. W. Zwiers, 2001: Statistical Analysis in Climate Research. Cambridge University Press, 484 pp.

Wilks, D. S., 2016: "The stippling shows statistically significant grid points": How research results are routinely overstated and overinterpreted, and what to do about it. Bull. Amer. Meteor. Soc., 97, 2263-2273, https://doi.org/10.1175/BAMSD-15-00267.1.

Woodruff, S. D., and Coauthors, 2011: ICOADS Release 2.5: Extensions and enhancements to the surface marine meteorological archive. Int. J. Climatol., 31, 951-967, https://doi.org/ 10.1002/joc. 2103 .

Woollings, T., 2011: Ocean effects of blocking. Science, 334, 612613, https://doi.org/10.1126/science.1214167.
B. Hoskins, M. Blackburn, and P. Berrisford, 2008: A new Rossby wave-breaking interpretation of the North Atlantic Oscillation. J. Atmos. Sci., 65, 609-626, https://doi.org/10.1175/ 2007JAS2347.1.

— A. Hannachi, and B. Hoskins, 2010: Variability of the North Atlantic eddy-driven jet stream. Quart. J. Roy. Meteor. Soc., 136, 856-868, https://doi.org/10.1002/qj.625.

, J. G. Pinto, and J. A. Santos, 2011: Dynamical evolution of North Atlantic ridges and poleward jet stream displacements. J. Atmos. Sci., 68, 954-963, https://doi.org/10.1175/ 2011JAS3661.1.

— variability. J. Climate, 31, 1297-1314, https://doi.org/10.1175/ JCLI-D-17-0286.1.

Zhang, R., and T. Delworth, 2006: Impact of Atlantic multidecadal oscillations on India/Sahel rainfall and Atlantic hurricanes. Geophys. Res. Lett., 33, L17712, https://doi.org/ 10.1029/2006GL026267.

R. Sutton, G. Danabasoglu, T. L. Delworth, W. M. Kim, J. Robson, and S. G. Yeager, 2016: Comment on "The Atlantic Multidecadal Oscillation without a role for ocean circulation." Science, 352, 1527, https://doi.org/10.1126/science.aaf1660. 